\title{
H-ZSM-5 Zeolite Model Crystals: Structure-Diffusion-Activity Relationship in Methanol-To-Olefins Catalysis?
}

Pit Losch, ${ }^{\mathrm{a}}$ Ana B. Pinar, ${ }^{\mathrm{b}}$ Marc G. Willinger, ${ }^{\mathrm{c}}$ Karel Soukup, ${ }^{\mathrm{d}}$ Sachin Chavan, ${ }^{\mathrm{e}}$ Bruno Vincent, ${ }^{\mathrm{f}}$ Patrick Pale, ${ }^{a}$ Benoît Louis ${ }^{a}{ }^{*}$

a) Laboratoire de Synthèse Réactivité Organiques et Catalyse, Institut de Chimie, UMR 7177 CNRS, Université de Strasbourg, 1 rue Blaise Pascal, 67000 Strasbourg cedex, France.

b) Laboratory of Crystallography, ETH Zurich, CH-8093 Zurich, Switzerland. Current affiliation: Laboratory of Catalysis and Sustainable Chemistry, Paul Scherrer Institute, CH-5232

Villigen, Switzerland.

c) Department of Inorganic Chemistry, Fritz Haber Institute of the Max Planck Society, Faradayweg 4-6, Berlin 14195, Germany.

d) Institute of Chemical Process Fundamentals of the CAS, v.v.i., Rozvojová 135, CZ-165 02 Prague 6, Czech Republic.

e) inGAP Center of Research Based Innovation, Department of Chemistry, University of Oslo, P.O. Box 1033, Blindern, 0315 Oslo, Norway.

f) NMR-service Strasbourg Institut de Chimie, UMR 7177, Université de Strasbourg, 1 rue Blaise Pascal, 67000 Strasbourg cedex, France.

\begin{abstract}
Large ZSM-5 zeolite crystals synthesized in fluoride medium show an astonishing activity, stability as well as selectivity towards light olefins in the Methanol-To-Olefins (MTO) reaction. By proper control of the synthesis parameters, ZSM-5 single crystals of unprecedented high quality are produced. The absence of usually uncontrollable variables such as structural defects, external non selective surface acid sites and extra-framework aluminum (EFAl) species was evidenced by SEM, HRTEM, CO-FTIR, ${ }^{27} \mathrm{Al}$ and ${ }^{19} \mathrm{~F}$ MAS-NMR, Rietveld structure refinement and $\mathrm{N}_{2}$ - and Ar-gas sorption measurements. Interestingly, diffusivity evaluation of different probe molecules (toluene, benzene and neopentane) has been carried out with PFG-NMR, allowing casting light on an interesting structurediffusion-activity relationship. A "levitation" effect could be experimentally demonstrated and its impact on catalysis is highlighted in a rationalization attempt: Maxwell-Boltzmann based diffusion models properly predict product distributions for this counter-intuitively outstanding Methanol-To-Propylene (MTP) catalyst.
\end{abstract}

Keywords: Structure-Diffusion-Activity, zeolite, ZSM-5, model catalyst, Methanol-to-Olefins (MTO).

* corresponding author. Email: blouis@unistra.fr (B. Louis) 


\section{Introduction}

Heterogeneous catalysis is of tremendous importance in today's chemistry but also in everyday life. Indeed, the most important chemical processes producing for instance ammonia via the HaberBosch process, sulphuric acid via the contact process, or gasoline through Fluid Catalytic Cracking (FCC) are heterogeneously catalyzed chemical transformations.[1,2] Precious insights have been gained in the understanding of heterogeneous surface catalysis, while studying perfect model catalysts culminating with the Nobel prize award to G. Ertl in 2007.[3] Even though it is often stated that defects may act as active sites in heterogeneous catalysts,[4] the latter approach led to an utmost degree of understanding. In spite of performing catalysis over a model catalyst, it is still possible to characterize surface defects and evaluate their impact in a reaction.[5]

Zeolites are crystalline, three-dimensional microporous aluminosilicates. The presence of defects as external silanols, Si-OH nests, intergrowths [6] and extra-framework Al species renders complicate a detailed surface understanding in a catalytic reaction. However, the synthesis of "perfect" zeolite crystals is all but trivial. With respect to aforementioned metal model catalysts, it remains nonetheless, wishful to reach a similar degree of understanding on the diffusion and reaction phenomena of molecules within zeolite pores.[7,8]

Among roughly 230 existing zeolites, ZSM-5 possessing a MFI-type structure remains one of the most studied and useful in industry. ZSM-5 main application is the production of light olefins, achieved via the catalytic cracking of hydrocarbons (FCC) and Methanol-To-Olefins (MTO) processes. In the latters, ZSM-5 allows a high selectivity towards light olefins, due to its particular three dimensional medium-sized channel topology. Light olefins are indeed important as building blocks for polymers or initial backbones for the synthesis of organic bulk chemicals such as amino acids.[9] Among them, propylene with 14.3 Mt produced per year remains the second topmost chemical in the U.S. today (80 Mt worldwide), right after sulphuric acid and ranked before sodium hydroxide or ammonia. It is therefore essential to achieve the highest selectivity towards light olefins, especially propylene. Consequently, the rational design of ZSM-5 zeolites to achieve high catalytic performances has become a frequent objective in acid catalysis.

In this challenging context, it would be beneficial to better understand the MTO reaction mechanism and how elevated selectivity can be achieved. Furthermore, the catalyst nature and quality certainly play a key role for achieving high selectivity, as the latter should be altered by the presence of high amounts of non-selective external acid sites. Coke formation and subsequent catalyst deactivation can also be strongly influenced by those external non-shape selective sites.[10,11] 
Considering the MTO-mechanism, Wragg et al. conducted an interesting study related to the reaction over SAPO-34 materials, where an ad operando study involving sophisticated diffraction and microscopic techniques led to significant mechanistic understanding.[12] Amazing progress on the understanding of SAPO-34 catalyzed MTO has been recently published by Saint Remi et al. who highlighted the importance of the impact of crystal diversity on mass transfers.[13] Recent progress in understanding complex surface chemistry mechanisms occurring during MTO using ZSM-5 catalysts is rather based on a combination of several spectroscopic methods (ad operando FTIR, UV-vis microspectrometry, ...) as well as computational modelling.[14,15] The prime C-C bond formation, which initiates an autocatalytic cycle, was under a severe debate until recently.[16,17] The dual cycle concept has been introduced by Bjørgen et al. leading to new insights and several interesting reviews are covering this topic (Scheme 1).[18,19,20] The essentials in brief, methanol is auto-catalytically reacting over ZSM-5 zeolites to form a hydrocarbon pool (HCP), which acts as a hybrid catalyst. This hydrocarbon pool is either working in an olefin-methylating-cracking or in an arene methylation and possibly side chain growth-cracking regime, or most likely a combination of both.

Additionally, detailed kinetic studies under industrially relevant conditions were performed in Lercher's group, to study the behavior of ZSM-5 zeolites in the MTO-reaction.[21,22] These seminal studies estimated reaction rates of intermediate steps,[23] unexpectedly indicating that hex-1-ene cracking may lead to a considerable formation of ethylene, whereas propylene is non negligibly produced by the cracking of aromatic side-chains. Consequently, a modified dual cycle concept arose.

Regarding the catalyst nature, the smaller catalyst particles are, the faster a reaction will proceed and overcome diffusional limitations.[24,25] However, the rise of nanometric catalysts is frequently accompanied with an increase in external and / or internal structural defects in addition to the presence of numerous non-selective external sites.[26] In this context, we will present herein the synthesis, characterization and counter-intuitive utility for the investigation of diffusion phenomena during catalysis of large and nearly perfect model ZSM-5 crystals. Indeed, a sound structure-diffusion-activity relationship for these large crystals in MTO-catalysis will be established.

Combining these earlier works, Armaroli et al. hypothesized that "high quality and low acidic ZSM-5 crystals should be powerful MTO-catalysts".[27] However, this hypothesis did not seem to have been evaluated nor ascertained. Therefore, and with the aim to synthesize an outstanding MTP-catalyst, we embarked in proving this hypothesis and we describe herein our results. In the present study, we report the synthesis and characterization of large and nearly perfect model ZSM-5 crystals, and its application as a particularly stable and highly selective catalyst for the methanol-to-propylene reaction. We also describe their counter-intuitive utility for the investigation of diffusion phenomena during catalysis, which allows deciphering a link between the high quality of as-obtained model crystals and 
their tremendous activity, selectivity, but more surprisingly long-term stability, observing unusual diffusion phenomena.

\section{Experimental}

\subsection{Chemicals}

All chemicals were used as received from the respective commercial supplier e.g. $\mathrm{CH}_{3} \mathrm{OH}$ and $\mathrm{CD}_{3} \mathrm{OD}$ from Aldrich and propylene gas from Gerling Holz \& Co (GHC).

\subsection{Zeolite synthesis}

ZSM-5 zeolites were synthesized in fluoride medium and the following parameters have been investigated: density of Brønsted acid sites, crystal size, chemical composition and crystalline quality. The so-called MFI-F catalyst was prepared via fluoride-mediated route adapted from our previous studies. The samples were named ZSM-5F respectively. All ZSM-5 samples obtained in $\mathrm{NH}_{4}$-form were calcined in static air during at least $6 \mathrm{~h}$ at $823 \mathrm{~K}$ to obtain their corresponding H-form. A typical ZSM-5 synthesis procedure was as follows (for instance Entry 2, Table S1): $70 \mathrm{~mL}$ of distilled water was poured in a $150 \mathrm{~mL}$-Erlenmeyer flask. Under vigorous stirring (700 rpm, r.t.), $\mathrm{NaAlO}_{2}(0.120 \mathrm{~g}), \mathrm{TPABr}$ $(0.907 \mathrm{~g})$ and $\mathrm{NH}_{4} \mathrm{~F}(2.020 \mathrm{~g})$ were consecutively added. Finally, $2.925 \mathrm{~g}$ of solid silica (Aeroperl $300 / 30$, Evonik) was slowly added during $5 \mathrm{~min}$. The $\mathrm{pH}$ of the gel was adapted to 7 by adding a few drops of a given acid (HF for ZSM-5FL/S/N and $\mathrm{HCl}$ for ZSM-5FLD see Table S1). The gel was aged under vigorous stirring (700 rpm, r.t.) for $2 \mathrm{~h}$. Meanwhile, the $\mathrm{pH}$ and fluoride anions concentration were monitored during ageing and after hydrothermal synthesis by means of Horiba LAQUAact pH/ORP/ION METER D-73 (Figure S1). The gel was then autoclaved at $443 \mathrm{~K}$ for 48 (ZSM-5FN and LD) or $144 \mathrm{~h}$ (ZSM-5FL and S).

Using larger autoclaves and scaling up syntheses while keeping similar gel compositions allowed the investigation of the impact of the synthesis volume. (cf. ZSM-5FN vs. ZSM-5FL, Fig.S2)

\subsection{Characterization}

X-ray diffraction (XRD) patterns were recorded on a Bruker D8 Advance diffractometer, with a Ni detector side filtered $\mathrm{Cu} \mathrm{K}$ radiation $\left(1.5406 \AA\right.$ ) over a $2 \theta$ range of $5^{\circ}$ to $60^{\circ}$. (Figure $\mathrm{S} 3$ )

Scanning Electron Microscopy (SEM) micrographs were acquired on a JEOL FEG 6700F microscope working at $9 \mathrm{kV}$ accelerating voltage. The $\mathrm{Si} / \mathrm{Al}$ ratios of the materials were determined by EDX analysis coupled with the SEM chamber, and separately by X-ray fluorescence using a SPECTRO XEPOS spectrometer equipped with a 50-Watt end-window X-ray tube to excite the samples. The target 
changer, with up to 8 polarization and secondary targets, offers many different excitation conditions ensuring optimum determination of all elements from $\mathrm{Na}$ to $\mathrm{U}$. The detection system consists of a 10 $\mathrm{mm}^{2}$ Si-Drift Detector (SDD) with Peltier cooling and a spectral resolution of less than $155 \mathrm{eV}$ at $\mathrm{Mn}$ $\mathrm{K} \alpha$ is achieved. Measurements were conducted in a $\mathrm{He}$ gas atmosphere. Acid site densities were evaluated by two complementary techniques; home-made H/D isotope exchange method which quantifies the totality of exchangeable hydrons,[28] and Temperature Programmed Desorption of npropylamine according to the method described by Gorte et al. which solely quantifies Brønsted acids characteristic for Si-(OH)-Al bridging sites (Table 1).[29]

The textural properties involving the BET surface area $\left(\mathrm{S}_{\mathrm{BET}}\right)$ were evaluated from classical nitrogen physical adsorption-desorption isotherms measured at $77 \mathrm{~K}$ by means of ASAP2020M equipment (Micromeritics). In addition, t-plot measurements were used to differentiate surface areas Prior to analysis, the samples were outgassed at $373 \mathrm{~K}$ for $1 \mathrm{~h}$ and $573 \mathrm{~K}$ for $15 \mathrm{~h}$ (Table 1).

The crystal size distribution was estimated by measuring 30 random c-axis lengths per zeolite using Image J software and previously obtained SEM-micrographs. These 30 measurements resulted in different Gaussian distributions representing the homogeneity of the crystal size distribution. Additionally, SEM micrographs were used to calculate crystal size distributions and respective Dispersities (Đ) using reported equations, $M$ being replaced by the crystal sizes.[30]

$\mathrm{Ð}=\mathrm{M}_{\mathrm{w}} / \mathrm{M}_{\mathrm{n}}$

$\mathrm{Ð}=(\mathrm{c} \text {-axis length })_{\mathrm{w}} /(\mathrm{c} \text {-axis length })_{\mathrm{n}}$

HRTEM images have been recorded using an image Cs corrected FEI TITAN transmission electron microscope that was operated at $300 \mathrm{kV}$. The sample for transmission electron microscopy was prepared by dipping a copper TEM grid with a holey carbon support film into the powder sample. Synchrotron powder diffraction data were collected on the Materials Science Beamline at the Swiss Light Source (SLS) in Villigen, Switzerland. [31] (Table S2) The indexing of the XRD patterns was performed using Topas,[32] which was also used for the Rietveld refinement (Table S3).[33] The structure drawings were produced using CrystalMaker [34] and the profile plots with the program ppp14.[35]

Samples with large enough crystal sizes $(20-100 \mu \mathrm{m})$ were observed by optical microscopy using a TRAVELER USB microscope allowing 10x 60x and 200x-fold magnification.

${ }^{19} \mathrm{~F}$ NMR were recorded on a on a Bruker MSL 300 spectrometer operating at $282.4 \mathrm{MHz}$ using a 4-mm Doty probe and single-pulse excitation. A pulse length of $4 \mu \mathrm{s}(\pi / 2)$ with a recycle delay of 6 or $10 \mathrm{~s}$ and a spinning rate of 7-8 kHz were used. ${ }^{19} \mathrm{~F}$ MAS NMR spectra were collected at both 13 and 15 $\mathrm{kHz}$ to assign spinning side bands. ${ }^{27} \mathrm{Al}(\mathrm{I}=5 / 2)$ MAS NMR was carried out with a Bruker Avance II 400 spectrometer operating at $\mathrm{B}_{0}=9.4 \mathrm{~T}$ (Larmor frequency $v_{0}=104.2 \mathrm{MHz}$ ) equipped with a Bruker 
$2.5 \mathrm{~mm}$ double channel probe. Samples were spun at $25 \mathrm{kHz}$, and free induction decays (FID) were collected with a $\pi / 12 \mathrm{rf}$ pulse $(0.5 \mu \mathrm{s})$ and a recycle delay of $1 \mathrm{~s}$. Measurements were carried out with $\left[\mathrm{Al}\left(\mathrm{H}_{2} \mathrm{O}\right)_{6}\right]^{3+}$ as external standard reference.

Infrared spectroscopy (FTIR) spectra were recorded in controlled atmosphere at $2 \mathrm{~cm}^{-1}$ resolution on a Bruker Vertex 80 FTIR spectrophotometer, equipped with a MCT detector and using a homemade IR cell. FTIR spectra were collected in transmission mode on a thin film prepared by deposition of zeolite water suspension on a silicon wafer. The difference in Brønsted acid strength of these samples was derived from CO adsorption. In order to compare the IR band intensities, spectra were normalized to the overtone mode at $2005 \mathrm{~cm}^{-1}$.

Textural analysis of ZSM-5 samples was performed by Ar adsorption-desorption experiments (Table S4). Micropore-size distribution was acquired from nitrogen physisorption measurements (Figure S4).

\subsection{Catalytic testing}

Prior to use, catalysts were calcined at $823 \mathrm{~K}$ with a gradient of $15 \mathrm{~K} \cdot \mathrm{min}^{-1}$ in static air. Hzeolites were sieved and particles $<250 \mu \mathrm{m}$ were used in the catalytic tests. $60 \mathrm{mg}$ of zeolite were introduced in a tubular quartz reactor, packed between quartz wool plugs. A methanol-saturated nitrogen-flow was fed to the reactor at $673 \mathrm{~K}\left(\mathrm{WHSV}=1.2 \mathrm{~g}\right.$ MeOH$\left.\cdot\left(\mathrm{g}_{\mathrm{cat}} \cdot \mathrm{h}\right)^{-1}\right)$. Samples withdrawn at the reactor outlet were analyzed by GC (HP5890 Series II, Pona column, $50 \mathrm{~m}$ ). The activity of the catalysts was expressed in terms of methanol and dimethylether conversion (Eq. 3), calculated from the difference between inlet and outlet concentrations of methanol (DME is therefore considered as an intermediate).

$$
X=\frac{\mathrm{n} \text { MeOH,in-(n MeOH out }+2 * \mathrm{n} \mathrm{DME})}{n \text { MeOH in }} * 100 \%
$$

The selectivity was defined as the mole ratio of each product referred to the moles of converted methanol and dimethylether. In (Eq. 4), $\alpha$ represents the number of C-atoms in the considered product, $(\Sigma)$ applied for the calculation of the selectivity towards light olefins $\mathrm{C}_{2}-\mathrm{C}_{4}$ fraction. In addition, the denominator corresponds to consumed methanol and dimethylether.

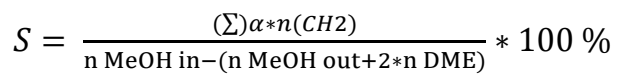

Conversions and selectivities were expressed after $1 \mathrm{~h}$ on stream (TOS), once the quasi steadystate was reached. Long-term stability experiments were performed on the same catalytic setup but at a WHSV of $2.5 \mathrm{~h}^{-1}$, to get an earlier full deactivation profile. In order to investigate molecular positive thermal expansion MTO experiments were carried out under steady state conditions using perdeuterated $\mathrm{d}_{4}-\mathrm{MeOD}$ since $\partial(\mathrm{d}(\mathrm{C}-\mathrm{D}))<\partial(\mathrm{d}(\mathrm{C}-\mathrm{H}))$ at high temperatures due to isotopic effects. 
A propylene-nitrogen gas mixture $\left(1 / 20 \mathrm{~mL} \cdot \mathrm{min}^{-1}\right)$ was fed to a zeolite containing reactor $(60 \mathrm{mg})$, under MTO conditions. Reaction conditions were chosen to set a theoretical $100 \%$ yield in propylene under aforementioned MTO conditions GHSV $=31.3 \mathrm{mmol}(\mathrm{C}) .(\mathrm{g} \text { (catalyst).h })^{-1}$.

\subsection{Pulsed Field Gradient (PFG)-NMR}

Measurement of toluene and benzene self-diffusion coefficients were performed on a Bruker 600 MHz spectrometer - Avance III, equipped with a high strength $\mathrm{z}$ gradient probe DOTY Scientific, developing a pulse field gradient of $50 \mathrm{G} / \mathrm{cm} / \mathrm{A}$. Experimental details are given in SI section.

\subsection{Modelling and microkinetics}

Simulations of inter active site diffusion lengths were carried out on a 4 unit cell model crystal which extends in the three space directions ( $a, b$ and $c)$. Molecular kinetic diameters were estimated with Spartan software, while their positive thermal expansion (PTE) was estimated considering each covalent bond as Newtonian behaving oscillator. $\gamma$, a confinement factor (Eq. 5) has been introduced which basically traduces the fit between any considered molecule, its temperature impacted diameter $\left(\varnothing_{\text {molecule(T) }}\right)$ due to PTE, and the microporous network with its temperature impacted diameter $\left(\varnothing_{\text {pore(T) }}\right)$ due to NTE:

$$
\gamma=\left(e^{-\left(1-\frac{{ }^{\circ} \text { pore }(T)}{{ }^{\operatorname{molecule}(T)}}\right)^{2}}\right)^{x}
$$

$\gamma$ 's function was chosen to be a bell shaped curve describing an optimal fit, with its maximum at 1 and minimum at 0 . The power $x \geq 1$ has been added to this function to attenuate the functions impact on the resulting diffusional velocity due to more or less selective fits, thus to allow the potential modelling of the degree of perfection or (micro)-porosity and the spheroidal shape of the considered molecule. This consequently leads to a possible change, due to confinement effects, in the speed distribution $\left(\mathrm{f}_{3 \mathrm{D}}(\mu)\right)$ and the most likely diffusional velocity $\left(\mu_{\mathrm{p}}\right)$ as depicted in Eqs. 6-7.

$$
\begin{aligned}
& f_{3 D}(\mu)=\sqrt{\left(\frac{p^{\gamma} * A}{2 \pi k T a}\right)^{3}} 4 \pi \mu^{2} e^{-\frac{p_{* A * \mu^{2}}}{2 k T a}} \\
& \mu_{p}=\sqrt{\frac{2 \pi k T a}{p^{\gamma} * A}}
\end{aligned}
$$

Interestingly, simple calculations show that $60 \mathrm{mg}$ of ZSM-5FL zeolite correspond to $0.19 \mathrm{~cm}^{3}$. However, the effective accessible volume is of $0.012 \mathrm{~cm}^{3}$ (microporous volume), hence the reactive volume is truly confined by a factor (at least) 10 . Hence, a certain impact of confinement in the MTO reaction appears plausible.

Shape selectivity should be observed leading to high amounts of butenes and probably some branched pentenes. However, the major product remains propylene on ZSM-5 zeolites. It is therefore of 
fundamental importance to analyze and understand the influence of temperature rise on molecular diameters (PTE) and (even) on the zeolite framework (NTE). Temperature related variations of zeolites porous diameters were estimated using the data from Cha et al. in their work on negative thermal expansion in high SAR ZSM-5 zeolites.[36]

We conversely used both, experimental $D_{\text {eff }}$ data and the above described $D_{\text {eff }}$ predictability for different molecules in different nanoporous solids to estimate unit-less microkinetics parameters.[37] Our main interest relied on the determination of Thiele-Weisz modulus $(\phi)$, which can be considered as the square root of the second Damköhler number, $\mathrm{Da}_{\mathrm{II}}$. The second parameter we estimated using our data was the Thiele-Weisz-Wagner-Wheeler degree of utilization $(\psi)$ of a porous catalyst.

$$
\begin{aligned}
& \Phi=L \sqrt{\frac{k c_{S}^{n-1}}{D_{e f f}}} \\
& \Psi=\Phi^{2} \eta=\frac{1^{2}}{\mathrm{D}_{\text {eff }} c_{\mathrm{A}}} \mathrm{r}_{\text {eff }}
\end{aligned}
$$

In Equations 8-9, $\mathrm{L}$ defines the diffusion pore-length $[\mathrm{m}], \mathrm{k}$ the reaction rate constant $\left[\mathrm{mol}^{-1} \cdot \mathrm{m}^{3}\right], \mathrm{c}_{\mathrm{S}}$ the surface concentration $\left[\mathrm{mol} . \mathrm{m}^{3}\right], \mathrm{n}$ the reaction order of the considered reacting molecule, $\mathrm{D}_{\text {eff }}$ the effective diffusivities measured by DOSY experiments and temperature-corrected using the above mentioned Maxwell-Boltzmann equations $\left[\mathrm{m}^{2} \cdot \mathrm{h}^{-1}\right], 1$ is the pore length $[\mathrm{m}], \mathrm{c}_{\mathrm{A}}$ the concentration of the considered substrate $\left[\mathrm{mol} \cdot \mathrm{m}^{-3}\right]$ and $\mathrm{r}_{\text {eff }}$ its related reaction rate $\left[\mathrm{mol} \cdot \mathrm{h}^{-1} \cdot \mathrm{m}^{3}\right]$.

\section{Results}

\subsection{Synthesis of perfect ZSM-5 crystals}

The introduction of fluoride anions in zeolite synthesis [38] provided milder conditions, producing larger crystals with less defects and more open structures with higher uptake of organocation and fluorine.[39] We thus prepared various ZSM-5 zeolites (named ZSM-5F) in fluoride aqueous solution at neutral $\mathrm{pH}$, under conditions adapted from our previous studies.[40,41,42] Several factors, such as silicon source, fluoride concentration, volume, $\mathrm{pH}$, chemical composition, were systematically evaluated (Table S1). To favor the formation of single, large (as perfect as possible) crystals, highly diluted gels were used.

Solid silica proved to be the best $\mathrm{Si}$ source in the presence of ammonium fluoride, as expected from a slow release of $\mathrm{SiO}_{\mathrm{x}} \mathrm{F}_{\mathrm{y}}{ }^{-}$species under diluted conditions. Such species in the presence of tetrapropylammonium bromide would lead to the formation of few nuclei, and thus to larger, high quality crystals (ZSM-5FL) (Figure S2). Monitoring the consumption of fluoride and the $\mathrm{pH}$ during ageing and zeolite formation confirmed these assumptions (Figure S1). Interestingly, varying synthesis volumes with similar gel compositions strongly impacted the size and quality of so-formed MFI 
crystals: smaller crystals (ZSM-5FS), the presence of defects (ZSM-5FLD), or both (ZSM-5FN) were observed at larger synthesis volumes. Shorter synthesis times (48h vs. 144h) obviously led to lower quality crystallites (ZSM-5FN and -5FLD vs. ZSM-5FS and -5FL). However, all as-prepared ZSM-5 zeolites in fluoride medium led to high crystalline yields (Table S1). Furthermore, the sole presence of the MFI-framework was ascertained by XRD (Figure S3). Besides, the quality of those crystals was evaluated by SEM observations (Figure 1) and their textural properties as well as Si/Al-ratios, theoretical and experimental Brønsted acid site (BAS) densities (strong BAS and total exchangeable hydrons) are reported in Table 1. These data exclude the presence of structural defects ( $\mathrm{Si}-\mathrm{OH}$ nests, EFAl-species etc.) in H-ZSM-5FL and H-ZSM-5FS samples (entries 2 and 3 in Table 1), whilst HZSM-5FN and H-ZSM-5FLD samples exhibit considerable amounts of non-BAS-linked exchangeable protons (entries 1 and 4).

In addition to the $\mathrm{S}_{\mathrm{BET}}$ and $\mathrm{S}_{\text {meso }}$ of the four samples, nitrogen adsorption-desorption measurements were performed and the sole presence of micropores for H-ZSM-5FL and H-ZSM-5FS was evidenced (Figure S4), whereas the microporous networks of H-ZSM-5N and H-ZSM-5FLD seem to be somehow obstructed, probably by various kinds of structural defects.

ZSM-5FS and ZSM-5FL exhibit a high crystalline quality as well as homogeneous sizes distribution (Figure 1). Likewise, a dispersity index close to unity was calculated for ZSM-5FS and ZSM-5FL samples. A deeper analysis of ZSM-5FL zeolite by HRTEM analysis (Figure 2) as well as Rietveld refinement (Figure 3) allowed proving an extremely high crystalline quality, plus excluding aluminum zoning and the subsequent formation of any core-shell structure.

The diffraction pattern of ZSM-5-FL sample was indexed in a primitive orthorhombic unit cell ( $a=$ 20.07309(6), $b=19.95733(6), c=13.40854(5) \AA)$, and the systematic absences were compatible with the Pnma space group, as previously reported.[43] An initial optimization of the geometry, using the published atomic coordinates, was performed using a distance-least-squares procedure.[44] A first difference electron density map showed a cross-shaped electron density cloud at the intersection of the two sets of 10-ring channels, so a $\mathrm{TPA}^{+}$cation was placed at that position with the $\mathrm{N}$ atom on the mirror plane perpendicular to the $b$ axis. The $\mathrm{C}$ atoms of two of the propyl moieties were also placed on that mirror plane because they refined to positions that were very close to it. A subsequent differences map showed an electron density peak in the $\left[4^{1} 5^{2} 6^{2}\right]$ cage that was interpreted as a fluoride ion located on the mirror plane perpendicular to the $b$ axis. The occupancy for this model refined to 0.35 for the $\mathrm{F}^{-}$anions (1.4 $\mathrm{F}^{-} /$u.c.) and 0.99 for $\mathrm{TPA}^{+}$, so it was set to $1\left(4 \mathrm{TPA}^{+} /\right.$u.c). This is in agreement with literature data.[45] Further refinement of this model with geometric restraints on bond lengths and angles for both the organic template and the framework yielded a reasonable geometry for the organic species and the framework. The crystallographic data for this structure are given in Table S3. The arrangement of TPA ${ }^{+}$ 
cations and fluoride anions within the MFI structure is shown in Figure 3. While two of the propyl arms lie on the mirror plane perpendicular to the $b$ axis, and point towards the sinusoidal 10-ring channel, the other two propyl arms point into the straight channel and their $\mathrm{C}$ atoms are disordered over two positions with equal probability. This location is similar to the one found in two different structure analyses using laboratory single-crystal data.[46] This is also the location of other organic molecules such as $o$-xylene [47] and $m$-xylene [48] that are not used as SDAs but adsorbed on a calcined ZSM-5 sample. The occupancy factors refined to 4 TPAs per unit cell and the location of fluoride anions in $\left[4^{1} 5^{2} 6^{2}\right]$ cages, a similar position to that found in a single crystal refinement of pure silica ZSM-5. However, in that case fluoride anions interact with one of the $\mathrm{Si}$ framework atoms $(\mathrm{Si}-\mathrm{F}=1.91 \AA)$, whereas in our case the shortest $\mathrm{Si}-\mathrm{F}$ distance is $2.38 \AA$. Therefore, that $\mathrm{Si}$ does not show longer $\mathrm{Si}-\mathrm{O}$ bond distances than the others, as usually found in case of $\mathrm{Si}-\mathrm{F}$ interaction. Neither extra-framework species were located, nor water molecules since only few molecules are expected to be present in such a hydrophobic zeolite (Table S3).

Figure 4 shows ${ }^{19}$ F MAS NMR spectra for ZSM-5FLD and ZSM-5FL zeolites and ascertained the presence of two types of fluoride anions in as-synthesized samples with two signals at -63 and $-79 \mathrm{ppm}$. In contrast to ZSM-5FLD, highly crystalline ZSM-5FL zeolite exhibits a higher amount of fluoride species corresponding to the signal at $-63 \mathrm{ppm}$ signal, whilst the signal at $-79 \mathrm{ppm}$ was more pronounced in the zeolite containing defects. ${ }^{19} \mathrm{~F}$ solid state NMR confirms therefore the presence of fluoride anions counterbalancing the positive charge of tetrapropylammonium cations (chemical shift at -64 ppm).[49] The signal with a chemical shift at - $79 \mathrm{ppm}$ is attributed to defects in the lattice. In the case of ZSM-5FL, the presence of octahedrally coordinated EFAl-species ( $\left.\mathrm{Al}_{\text {oct. }}\right)$ could be excluded by ${ }^{27} \mathrm{Al}$ MAS NMR (Figure 4, insert), since no signal could be detected at $0 \mathrm{ppm}$. $\mathrm{Al}_{\text {oct. }}$ species were, however, detected for H-ZSM-5FLD.

Low temperature $\mathrm{CO}$ adsorption followed by FT-IR revealed the presence of a considerable amount of EFAl species, a clear peak at $2164 \mathrm{~cm}^{-1}$, as well as some external and internal silanol defects (signal at $3700 \mathrm{~cm}^{-1}$ ) in ZSM-5FLD zeolite (Figure 5a).[49] In contrast, H-ZSM-5FL crystals neither exhibit a signal for silanol defects nor the presence of EFAl-species. Hence, solely bridging Si-OH-Al BAS are present within this zeolite: as shown a sharp peak at $3619 \mathrm{~cm}^{-1}$ in the $\mathrm{OH}$ region and at $2174 \mathrm{~cm}^{-1}$ in the $\mathrm{CO}$ stretching region of the spectrum (Figure $5 \mathrm{~b}$ ).

These extensive characterizations of as-prepared zeolites clearly revealed the high quality of $\mathrm{H}$ ZSM-5FS and H-ZSM-5FL, with respect to H-ZSM-5FN and H-ZSM-5FLD. Especially H-ZSM-5FL appears as giant, but perfect crystals and therefore a promising, if active, model catalyst. In this study it will prove this potential in the MTO-reaction. 


\subsection{Methanol-to-Hydrocarbons reaction}

All the so-formed different ZSM-5 zeolites were then evaluated as catalysts in the transformation of methanol into olefins.

Table 2 presents the methanol (and dimethylether) conversion over calcined catalysts along with the selectivities towards the different hydrocarbons. H-ZSM-5FN, led to typical product distribution at full methanol conversion, producing a propylene / ethylene ratio of 2.4 in line with commercial catalysts.[50] Indeed, relatively high amounts of paraffins and aromatics were readily formed, suggesting the main occurrence of aromatics-based autocatalytic cycle for H-ZSM-5FN and H-ZSM5FLD (entries 1 and 4 Table 2), while the two H-ZSM-5FS and H-ZSM-5FL perfect samples (entries 2 and 3) exhibit a product distribution typical for an alkene-based autocatalytic cycle.

H-ZSM-5FL (Table 2, entry 3) led to the highest propylene selectivity; i.e. 45\%. It needs to be mentioned at this point that no significant differences concerning either the characterization (apart from the different crystallite sizes) or the catalytic behavior could be noticed between the former ZSM-5FL and ZSM-5FS perfect zeolites. Herein designed model catalysts may thus range from $0.5 \times 1 \times 5 \mu \mathrm{m}^{3}$ (ZSM-5FS) to $10 \times 15 \times 40 \mu \mathrm{m}^{3}$ (ZSM-5FL) in their respective crystal sizes. For later in situ or ad operando analyses as model catalysts, the as-obtained large crystals constitute the most promising candidate.[7] Therefore, the following part of the study will focus on the three catalysts H-ZSM-5FN, H-ZSM-5FLD and H-ZSM-5FL. H-ZSM-5FN is smaller in size than ZSM-5FS, which led to a sample with a significant amount of defects and external non-shape selective acid sites, H-ZSM-5FLD is composed of large crystals with a significant amount of structural defects potentially interfering during catalysis. On the other hand, H-ZSM-5FL constitutes large perfect model crystals with a unique homogeneity in acid site dispersion and crystalline quality. The latter exhibits exclusively microporosity and solely highly dispersed Brønsted acid sites, and furthermore in terms of stability it out-competes the other samples (Figure 7d).

Interestingly, an experiment flowing per-deuterated $\mathrm{d}_{4}$-MeOD through H-ZSM-5FLD zeolite (Table 2, entry 5) evidenced an isotopic effect (with respect to entry 4). Figure 6 shows the distribution of products obtained at full $\mathrm{d}_{4}-\mathrm{MeOD}$ - (a) or MeOH-conversion (b) over H-ZSM-5FLD zeolite at different temperatures. The stronger and shorter C-D bond led to a different product distribution compared with $\mathrm{C}-\mathrm{H}$ bond, especially in favour of propylene formation, achieving a $\mathrm{C}_{3=- \text {-selectivity }}$ comparable to H-ZSM-5FL (with $\mathrm{MeOH}$ ). However, during this experiment still almost twice as much ethylene is observed over this catalyst than over H-ZSM-5FL. Several effects may be involved in this experiment. First the stronger C-D bond may be limiting hydrogen-transfer (HT) reactions (in the given case, deuterium-transfer (DT) is typically occurring 6 - 10 times slower than HT due to a kinetic isotopic effect (KIE). [51] This is favouring an alkene-based autocatalytic cycle. However, since this is 
not explaining per se the high propylene and the still high ethylene selectivity, shorter C-D bonds leading to smaller olefins may play a role as well. An explanation could be assessed from the steric isotopic effects (SKIE). In the latter SKIE, an overall smaller amplitude of vibration for C-D bonds as compared to $\mathrm{C}-\mathrm{H}$ bonds induces smaller van der Waals radii or effective molecular sizes.[52,53] Likewise, Westheimer demonstrated, with a carbon-hydrogen stretching frequency of $2900 \mathrm{~cm}^{-1}$ and carbon-deuterium frequency of about $2100 \mathrm{~cm}^{-1}$, a difference of a factor 7 difference in reaction rates. [53b] In other words, shorter C-D bonds leading to smaller olefins may influence as well the selectivity towards smaller olefins.

Therefore, in defects containing ZSM-5FLD, where (C-H)-MTP is not working properly, the combination of the two aforementioned effects allows an optimal diffusion of smaller olefins and thus the observation of a (C-D)-MTP.

Based on recent studies on Diels Alder reaction, where an optimal fit was found between the two protagonists, methylacrylate and isoprene, and the MFI zeolite framework (at low temperatures < $90^{\circ} \mathrm{C}$ ), one may suggest a possible enhanced diffusivity of certain molecules in those large crystals. [54] In our case, we chose to study propylene, the target and major product formed over ZSM-5FL, which has been used as a reactant to evaluate its conversion under MTO conditions (Figure 7). The fluoridesynthesized catalysts converted propylene above $300^{\circ} \mathrm{C}$ (other products than propylene appear in the product distribution). At temperatures above $400^{\circ} \mathrm{C}$ (MTO conditions), propylene is detected as major product again, indicating either a reaction producing selectively propylene or simply its fast diffusion through the completely microporous network, which perfectly fits the considered molecular diameter of propylene. A large and defect-free crystal with highly dispersed acid sites may warrant a proper sorption of propylene within the pores, reducing the degrees of freedom of sorbates, manifested by a (limited) decrease in entropy.[54a]

Nuclear magnetic resonance (NMR) spectroscopy is known for decades for having casted light on molecular behaviour in confined environment of large ZSM-5 crystals.[55] More recently, Pulsed Field Gradient (PFG)-NMR spectroscopy has been reported as a powerful tool to measure molecular diffusivities in porous materials such as zeolites under ambient conditions. This technique has allowed the discrimination between mesoporous and microporous diffusion.[56,57] In order to underline our rising suspicion that high quality H-ZSM-5FL zeolite seems to be a valuable candidate as a model, active and stable MTP-catalyst, we performed Pulsed Field Gradient (PFG)-NMR spectroscopy with different probe molecules, i.e. toluene, benzene and neopentane. The latter was selected as a model of the MTO compounds, while the two other were used for comparison purposes. Figure 8 presents effective diffusivities of three different probe molecules, which were measured over the three studied zeolites. The most commonly studied probe molecule toluene (Fig. 8a) exhibits two different 
diffusivities, which can be attributed to intercrystalline, mesoporous diffusion for the $10^{-8} \mathrm{~m}^{2} \cdot \mathrm{s}^{-1}$ part (for H-ZSM-5FN) and to intracrystalline, microporous diffusion in the range of $10^{-9} \mathrm{~m}^{2} \cdot \mathrm{s}^{-1}$ (for the three samples). The latter value is in agreement with what has been shown by adsorption-desorption measurements coupled with infrared spectroscopy.[58] Several spectra were recorded at different diffusion times for H-ZSM-5FL zeolites, exclusively containing micropores (Figure S5). The linear fit between $D_{\text {eff. }}$ and diffusion times indicates a confined diffusion within the microporous network. It is important to note that, in a non-confined environment, measured diffusivities do not vary while varying diffusion times. These results validate the fact that ZSM-5FL's large crystal sizes combined with NMR time-measurement experiments are adequate tools to monitor the intracrystalline, truly microporous diffusion.

In Figure 8b, the effective diffusivities of benzene behave the same way than those of toluene, with microporous diffusion (for the three samples) and supplementary mesoporous diffusion (for $\mathrm{H}$ ZSM-5FN). Lastly, in Figure 8c, where neopentane's diffusivities are assessed, a surprising result was observed. In H-ZSM-5FN, the quasi-spherical molecule, which perfectly fits ZSM-5's micropores (under room temperature conditions), neopentane is diffusing at $605^{*} 10^{-9} \mathrm{~m}^{2} \cdot \mathrm{s}^{-1}$, [59] whereas for the larger high quality crystals, it seems to diffuse roughly three-times faster (at $1710^{*} 10^{-9} \mathrm{~m}^{2} \cdot \mathrm{s}^{-1}$ ) in $\mathrm{H}$ ZSM-5FLD and most impressively, four times faster (at $2621 * 10^{-9} \mathrm{~m}^{2} \cdot \mathrm{s}^{-1}$ ) in the perfect, model H-ZSM5FL. Thus, the previously observed tendency $\mathrm{D}_{\text {eff }}(\mathrm{H}-\mathrm{ZSM}-5 \mathrm{FLD})=\mathrm{D}_{\text {eff }}(\mathrm{H}-\mathrm{ZSM}-5 \mathrm{FLD})<\mathrm{D}_{\text {eff }}(\mathrm{H}-$ ZSM-5FN) seems to be inversed, with the following order $D_{\text {eff }}(H-Z S M-5 F L)>D_{\text {eff }}(H-Z S M-5 F L D)>$ $\mathrm{D}_{\text {eff }}(\mathrm{H}-\mathrm{ZSM}-5 \mathrm{FN})$. It is necessary to note that for each probe molecule the diffusivity-distribution is larger for the defect-containing zeolite, as compared to the perfect ZSM-5FL sample. The herein studied model catalyst ZSM-5FL hence allowed to experimentally observe an utmost rare phenomenon: neopentane diffused inside ZSM-5's micropores like a "floating molecule" or levitated as it has been predicted by Derouane et al. and already attempted to be experimentally proven on NaX zeolite.[60,61] In the next part, this structure-diffusion relationship will be linked to the surprising activity, product distribution and stability of as-designed model ZSM-5FL catalyst.

\section{Discussion}

Zeolite topologies are known to be a key factor regarding their activity and selectivity in catalysis. Even though, comparing different pore architectures is a good starting point, zeolites among one particular zeolite topology usually exhibit different crystal sizes, acid site densities and crystalline qualities. Additionally, it is well known that those key parameters may play important roles in activity and selectivity in acid-catalyzed reactions. 
Herein, we focused on the synthesis and application of "perfect" model crystals possessing highly dispersed acid sites, which are active in the conversion of methanol into hydrocarbons and highly selective toward propylene. In sharp contrast to what was expected, we could establish, thanks to the thorough characterization and catalytic data, that an almost perfectly crystallized zeolite, with a low Brønsted acid site density and a very large crystal size, is in fact an optimum to design a ZSM-5 catalyst for the MTP process. This paradigm change is fully counter-intuitive, since large crystals normally limit catalyst activity due to diffusional limitations of aromatics or relatively large olefins.

In the following part, we attempt to explain this interesting catalytic behavior, its corresponding product distribution and long-term stability using our data and various reported tendencies concerning material physics and confinement linked shape selectivity. Furthermore, it is important to note that our approach proposes a complementary model catalyst compared to related studies in Weckhuysen's group with model large ZSM-5 catalysts in the MTO-reaction, which either exhibit structural defects,[62] a significantly higher acid site density $(\mathrm{Si} / \mathrm{Al}<30)[63]$ and larger crystal sizes $\left(20 \mathrm{x} 20 \times 100 \mu^{3}\right.$ implying a higher probability for more defects). [64,65]

As mentioned above for neopentane's diffusion (Fig.8c), the concept of diffusional supermobility has already been evoked in the 1950's.[66,67] This concept is based on the movements of a molecule exempted from any constraint. Depending on its length and diameter, a molecule can move with respect to its rotational and vibrational degrees of freedom more or less rapidly in non-confined 3D space. However, a sorbed molecule in a porous host will suffer limitations in its movements and when its dynamical diameter (Fig.S6a) equals the porous diameter, then only two directions (forwards and backwards) are left to diffuse (as for neopentane under ambient conditions, or propylene under MTP conditions). Hence its apparent diffusion may become "superfast", as illustrated in Figure S6b. Such effects are intrinsic to the confinement theory and are reported to influence product distribution during zeolite catalysis. [68] In contrast to Ryoo's work with 2-unit cell thick MFI crystals, where mass transfer limitations could be excluded, [69] and regarding the above, it becomes imaginable that our crystals with more than 5000 MFI unit cells in the crystalline a- and b-axes parallel to MFI's micropores might neither be limited by mass transfer.

Indeed we observed in our MTO-studies that the quality of the crystals had an impact on the diffusion of molecules in the microporous network. In those experiments, the fewer defects were, the better catalytic performance was observed for as-made materials. Furthermore, a correlation could be established between the propylene selectivity and the (detrimental) presence of defects.

Therefore, it seems that free diffusion could be hindered by any kind of defects, such as the common presence of EFAl species or silanol defects. More surprisingly, high acid site density may also be considered as a defect. Indeed, statistics based on the characterization of ZSM-5FLD and ZSM-5FL's 
porosities (Figure S4, Table S4) show that the mean diffusion path in ZSM-5 zeolites would be strongly influenced by different Si/Al-ratios (Figure 9). This model also shows that in ZSM-FL type materials, a molecule diffusing through the microporous network would diffuse through at least 5-6 channel intersections before encountering the next nearest acid site. This pathway would thus hinder further reactions and therefore improve the selectivity.

The aforementioned concept of diffusional supermobility, or levitation is obviously also linked to the size and shape of the diffusing molecule. Interestingly, our MTO studies also suggest that molecular size plays a key role in this transformation. Indeed, the perdeuterated methanol experiment (Figure 6) showed that, under equilibrium conditions, the molecular apparent sizes can lead to a change in the product distribution, shifted towards the production of diffusion-enhanced olefins.

Moreover, the experiment with propylene fed at different temperatures (Figure 7) showed as well that the production and diffusivity of propylene is enhanced at MTO/P relevant conditions, leading to the same conclusion.

Figure S6a explains why we may consider light olefins, the main products during the MTO-reaction as spheroidal molecules, enabling in turn the theoretical implementation of the levitation concepts. Figure S6c then, plots the theoretically predicted mean diffusional velocities using the later developed Eq. 21 for the different light olefins once in free space and once in a sphere-in-a-cylinder confined space.

The impact of higher apparent diffusivities is also true for the transition state level of adsorbed species. Recently, Lercher demonstrated that "adsorbed transition state species" on strong (as shown above, highly dispersed in ZSM-5FL) acid sites are all but static. [70] Especially at high temperatures, those 'protons' in zeolites can be assimilated to superacids. [71]

Krossing et al. [72] demonstrated the possible exalted mobility of cations on weakly coordinating anions. The ZSM-5FL framework possessing a high SAR without defects can be assimilated to a solid weakly coordinating anion, thus the main product propylene in its adsorbed state may diffuse rapidly (as well as its protonated form), whereas protonated butylenes and other olefins exhibit longer residence times within the large crystals and can react further, forming even more propylene (Figure 7a, b and c). Under those quasi steady-state conditions, it is therefore reasonable to expect a negligible contribution of adsorption / desorption processes with respect to diffusion of propylene within the crystal.

Despite its complexity, [73] the reaction kinetics of the MTO elementary reactions on ZSM-5 zeolites are well studied. Detailed reaction rates for methylation and cracking steps in the autocatalytic MTO reaction have been determined. [14,22] In terms of reactivity for methylation $\left(\mathrm{R}_{\text {meth. }}\right)$, the following tendency is observed: $R_{\text {meth. }}\left(C_{2}=\right)<R_{\text {meth. }}\left(C_{3}=\right)=R_{\text {meth. }}\left(C_{4}=\right)$. In a simplistic assumption, where MTP runs in an olefin-based autocatalytic cycle, our catalytic results suggest, in order to 
compensate for the observed product distribution, and especially in our large crystals that effective diffusivities in ZSM-5 zeolite should be as follows: $\mathrm{D}_{\text {eff }}\left(\mathrm{C}_{3}=\right)>\mathrm{D}_{\text {eff }}\left(\mathrm{C}_{2}=\right)=\mathrm{D}_{\text {eff }}\left(\mathrm{C}_{4=}\right)$.

Additionally, under MTO conditions $\left(>400{ }^{\circ} \mathrm{C}\right)$, sufficient thermal energy is provided to methylate and crack any given olefin. However, the entropic part is highly impacted by the moleculepore interactions and its impact on the Gibbs enthalpy of activation is directly linked to the reaction temperature.[74,75] The reaction is thus ruled by an optimum between Gibbs free energy barriers of diffusion and of previous, intermediate or subsequent reactions. Hence, in the case of H-ZSM-5FL (Eqs.10-11):

$\Delta\left(\mathrm{D}_{\text {eff }}\right)>\Delta\left(\mathrm{R}_{\text {meth./rack. }}\right)[76]$

$\Delta \mathrm{G}_{\mathrm{act}}=-\mathrm{R} \cdot \mathrm{T} \cdot \ln \mathrm{K}=\Delta \mathrm{H}_{\mathrm{act}}-\mathrm{T} \cdot \Delta \mathrm{S}_{\mathrm{act}}$

The reaction can be described by the following equilibrium constant $\mathrm{K}$ (Eq. 12) considering the partial pressures of reactants and products:

$K=\frac{p_{i}\left(C_{2=}\right)^{a} p_{i}\left(C_{3=}\right)^{b} p_{i}\left(C_{4=}\right)^{c} p_{i}\left(C_{n=}\right)^{d} p_{i}\left(H_{2} O\right)^{e}}{\left(p_{i}(\mathrm{MeOH})+p_{i}(D M E)\right)^{e}}$

We thought worthy to investigate the influence of positive thermal expansion (PTE) of molecules, negative thermal expansion (NTE) of porous materials, along with a Maxwell-Boltzmann distribution of diffusional velocities ( $\mu$ ) (Eq. 14), to provide an empirical understanding of an optimal fit of a molecule within pores and its related enhancement in apparent effective diffusivities. Likewise, its impact on the above-mentioned equilibrium constant (Eq. 12) has to be studied. As a general finding, a well-defined porous network may induce an apparent decrease in the partial pressure of a floating molecule (Eq. 13), thus leading to a shift in the thermodynamic equilibrium towards the formation of this molecule (Fig.S6c). The quasi-steady state observed under MTO reaction conditions is strongly shifted towards the production of light olefins; therefore Eq. 12 might better describe the interconversion (via the dual cycle) of light olefins. In addition, ZSM-5FL is rather hydrophobic and should favour (with respect to defective crystals) a continuous water release from the porous network and therefore shift the equilibrium toward products formation. Considering now, the product distribution, or in other words, the high propylene selectivity, a fluid supermobility concept can be applied to explain this unexpected behaviour.

As $\mathrm{p}_{\text {conf. }} \rightarrow 0$

The general speed distribution will be impacted as follows:

$$
f_{3 D}(\mu)=\sqrt{\left(\frac{m}{2 \pi k T}\right)^{3}} 4 \pi \mu^{2} e^{-\frac{m \mu^{2}}{2 k T}}
$$


with $\quad p(T)=\frac{F}{A}=\frac{m a(T)}{A}$

Here, $F$ is a force, $A$ an area and $m$ the considered molecule's mass, while $a$ is the scalar of molecular acceleration, the derivative of the velocity as a function of time, without a variation results in a constant.

so $\quad m=p * \frac{A}{a}$

Hence $f_{3 D}(\mu)=\sqrt{\left(\frac{p * A}{2 \pi k T a}\right)^{3}} 4 \pi \mu^{2} e^{-\frac{p * A * \mu^{2}}{2 k T a}}$

Now we are introducing $\gamma$ (varying between 0 and 1 and impacting partial pressures), to basically

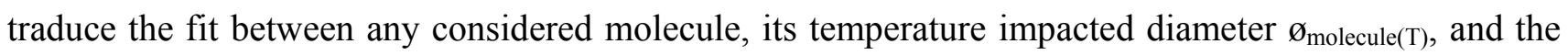
microporous network with its temperature impacted diameter $\emptyset_{\text {pore }(\mathrm{T})}$ :

$$
\begin{aligned}
& \gamma=\left(e^{-\left(1-\frac{{ }^{\text {pore }}(T)}{\phi_{\text {molecule }(T)}}\right)^{2}}\right)^{x} \\
& f_{3 D}(\mu)=\sqrt{\left(\frac{p^{\gamma} \cdot A}{2 \pi k T a}\right)^{3}} 4 \pi \mu^{2} e^{-\frac{p^{\gamma} \cdot A \cdot \mu^{2}}{2 k T a}}
\end{aligned}
$$

Leading to the most likely diffusional velocity:

$$
\mu_{p}=\sqrt{\frac{2 \pi k T a}{p^{\gamma} \cdot A}}
$$

Considering all the constants above (A, $2 \pi$, $\mathrm{k}$ and a), they are replaced by $c$ and $c^{\prime}$, equations simplify in turn to the following:

$$
\begin{aligned}
& f_{3 D}(\mu)=\sqrt{\left(c \cdot p^{\gamma}\right)^{3}} c^{\prime} \cdot \mu^{2} e^{-p^{\gamma} \cdot c \cdot \mu^{2}} \\
& \mu_{p}=\sqrt{\frac{1}{p^{\gamma} \cdot c}}
\end{aligned}
$$

By considering aforementioned confinement-linked pressure variation, it is possible to visualize its impact on the effective diffusional speed by applying the Maxwell Boltzmann distribution and to model it for $\mathrm{C}_{2}=-\mathrm{C}_{4=}$ olefins either for the normal pressure or for a confinement-impacted apparent partial pressure (Fig.S6c).

As depicted on Figure S6a, dynamic radii were estimated considering vibrational modes (stretching, bending etc.) at high temperatures, and with each $\mathrm{C}-\mathrm{C}$ or $\mathrm{C}-\mathrm{H}$ bond is considered to follow Newtonian mechanics. In free space, olefins behave like oscillating expanding spheres with an expansion being a function of temperature (between $293 \mathrm{~K}$ and $773 \mathrm{~K}$ ) from 3.5 to $4.5 \AA$ for ethylene, 4.2 to $5.7 \AA$ for propylene and 5.4 to $7.3 \AA$ for butylene. Besides this positive thermal expansion (PTE) phenomenon, the inverse one, i.e; negative thermal expansion (NTE) is frequently encountered for crystals. Once heated, porous crystals are known to contract, since the stretching vibrational mode has no impact in a crystal; the bending and twisting modes of Si-O-Si and Si-O-Al bonds lead to a net 
decrease in total crystal volume and in accessible volume. This has been elegantly studied and reported for ZSM-5 crystals exhibiting low acid site density by Cha et al.[36] As this volume variation is again due to vibrational modes, this phenomenon occurs in an oscillating manner. The MFI zeolite pore dimensions in crystalline a-axis may hence vary between; 5.500, 5.473 and $5.445 \AA$ for the respective temperatures 273,523 and $773 \mathrm{~K}$.

Under MTO reaction conditions, a certain harmonization of the oscillations between the dynamic (propylene) molecular diameter and the accessible microporous diameter can be assumed. By considering methanol and MTO products as ideal gases, we can calculate the most probable speed for each molecule in free and in microporous confined space, using our derived confinement impacted Maxwell Boltzmann distribution (Figure S6c, Eq. 21-22).

On a non-shape selective catalytic surface, ethylene would preferentially escape if compared to larger olefins. The impact that a pronounced degree of confinement has on diffusion speeds is higher for propylene than for ethylene and butylene (Figure S6c). The considered molecule may indeed diffuse faster than ethylene, and more interestingly $\mathrm{C}_{3}=/ \mathrm{C}_{2}=$ ratios as experimentally observed can be modelled using our developed equations (Eq. 21-22). Propylene's favourable production during MTP becomes therefore predictable using this diffusion model and considering the impact of the degree of confinement $\gamma$.

With our experimental data obtained from PFG-NMR experiments and aforementioned considerations in hand, we have estimated the Thiele modulus ( $\phi$ ) (Table S5) and Thiele-WeiszWagner-Wheeler degree of utilization $(\psi)$ (Table S6) for the ZSM-5F catalyst series, estimated for the following probe molecules methanol, propylene, toluene and trimethylbenzene. These estimations allowed us to conclude that our olefin producing large crystals are definitely not limited by intracrystalline diffusion. Only medium to large aromatics over the defects containing large crystals lead to a pronounced inhibition by molecular diffusion within the crystal. However, it has to be mentioned that these aromatics do not have to diffuse out of the pores in the MTO multi-step reactions, since they are produced and further react inside the microporous network.

Under steady-state conditions, considering all the data presented herein, our large ZSM-5FL catalyst selectively producing propylene led us to allude its behaviour in catalysis to an organ pipe which under certain conditions (temperature, diameter and length) produces selectively a certain note.[77]

In fine, the rational design of MTO catalysts led us to find an outstanding MTP catalyst, and allowed us to investigate and present a global picture of well-studied elementary steps occurring during MTO on ZSM-5 catalysts. The gained results also allowed us to validate the Armaroli et al. hypothesis (see introduction) and the "floating" molecule concept, as well as proposing a model for the latter. 
Besides, the synthesis of such highly ordered material opens another set of applications as, for example, a single crystalline model catalyst (Figure S7), with periodically arranged acid sites (if mass transfer limitations can be neglected). The latter could also demonstrate a huge potential for crystallographic studies, thanks to its high periodicity, especially by solving the structure of trapped molecules.[78] Lastly, large defect-free zeolite crystals also work as excellent host-guest materials for performing supramolecular chemistry.[79]

\section{Conclusion}

Large and defect-free ZSM-5 zeolite crystals were synthesized in fluoride medium. The latter catalysts demonstrated a high activity, stability as well as selectivity towards light olefins in the Methanol-To-Olefins (MTO) reaction. By properly controlling the synthesis parameters, ZSM-5 zeolite single crystals exempted from ubiquitous structural defects, i.e. external and internal silanols, extraframework aluminium (EFAl) species, were obtained.

The present study highlights a detailed characterization (SEM, HRTEM, CO-FTIR, ${ }^{27} \mathrm{Al}$ and ${ }^{19} \mathrm{~F}$ MAS-NMR, Rietveld structure refinement, BET and PFG-NMR techniques), application and subsequent rationalization of these ZSM-5F zeolites as promising MTP (Methanol-To-Propylene) catalysts. Interestingly, the perfect large crystals (H-ZSM-5FL) behaved in a counter-intuitive manner in catalysis, being very selective towards propylene, very active and the most stable catalyst.

This study presents the surprising utility of perfect large H-ZSM-5 zeolites as promising MTP catalysts but as well as model catalysts. They were used for a diffusivity evaluation of different probe molecules (toluene, benzene and neopentane) with PFG-NMR, allowing to shed light on an interesting structure-diffusion-activity relationship, large perfectly microporous crystals led to unusually high permeabilities for small molecules (such as neopentane or propylene under MTP-catalytically relevant conditions). A "levitation" effect could be experimentally demonstrated and its impact on MTOcatalysis has been highlighted using Maxwell-Boltzmann based diffusion models.

\section{Acknowledgments}

Rachel Heyard is greatly acknowledged for sharing her experience in statistics. PL would like to thank the National Research Fund Luxembourg for his PhD grant (5898454). Séverinne Rigolet (IS2M, UHA Mulhouse) is gratefully acknowledged for MAS-NMR measurements. The authors thank Nicola Casati and Antonio Cervellino from the Material Science beamline at SLS in Villigen, Switzerland, for their assistance with the powder diffraction measurement. A.B.P. is deeply grateful to Lynne McCusker for her endless patience to show her the secrets of Rietveld refinement. 
[1] I. Fechete, Y. Wang, J.C. Vedrine, The past, present and future of heterogeneous catalysis, Catal. Today. 189 (2012) 2-27.

[2] Zeolites and Catalysis, Synthesis, Reactions and Applications, J. Cejka, A. Corma, S. Zones, Wiley-VCH, Weinheim; 2010.

[3] Reactions at surfaces: From atoms to complexity, G. Ertl, Nobel Lecture, December 8, 2007.

[4] M. Behrens, F. Studt, I. Kasatkin, S. Kühl, M. Hävecker, F. Abild-Pedersen, S. Zander, F. Girgsdies, P. Kurr, B.L. Kniep, M. Tovar, R. W. Fischer, J. K. Nørskov, R. Schlögl, Science 759 (2012) 893.

[5] D.Y. Murzin, in Engineering Catalysis, de Gruyter, Berlin, 2013.

[6] L. Karwacki, M.H.F. Kox, D.A.M. de Winter, M.R. Drury, J.D. Meeldijk, E. Stavitski, W. Schmidt, M. Mertens, P. Cubillas, N. John, A. Chan, N. Kahn, S.R. Bare, M. Anderson, J. Kornatowski, B.M. Weckhuysen, Nat. Mater. 8 (2009) 959.

[7] Z. Ristanović, J.P. Hofmann, G. De Cremer, A.V. Kubarev, M. Rohnke, F. Meirer, J. Hofkens, M.B.J. Roeffaers, B.M. Weckhuysen, J. Am. Chem. Soc. 137 (2015) 6559.

[8] C.J.H. Jacobsen, C. Madsen, J. Houzvicka, I. Schmidt, A. Carlsson, D. Lyngby, J. Am. Chem. Soc. 122 (2000) 7116.

[9] (a) Chemical and Petroleum Manufacturers of India, Data for 2012. (b) American Chemical Council 2013 Statistics. Data for 2012. (c) APPE (Association of Petroleum Producers in Europe). Data for 2012, (d) Data from IHS 2011.

[10] B. Smit, T.L.M. Maesen, Nature 451 (2008) 671.

[11] P.J. Kunkeler, D. Moeskops, H. van Bekkum, Microporous Mater. 6513 (1997) 313.

[12] D.S. Wragg, M.G.O. Brien, F.L. Bleken, M. Di Michiel, U. Olsbye, Angew. Chem., Int. Ed. 51 (2012) 7956.

[13] J.C. Saint Remi, A. Lauerer, C. Chmelik, I. Vandendael, H. Terryn, G. V. Baron, J.F.M. Denayer, J. Kärger, Nat. Mater. 15 (2015) 401.

[14] X. Sun, S. Mueller, Y. Liu, H. Shi, G.L. Haller, M. Sanchez-Sanchez, A.C. van Veen, J.A. Lercher, J. Catal. 317 (2014) 185.

[15] K. Hemelsoet, Q. Qian, T. de Meyer, K. de Wispelaere, B. de Sterck, B.M. Weckhuysen, M. Waroquier, V. van Speybroeck, Chem. Eur. J. 19 (2013) 16595.

[16] J.F. Haw, W. Song, D.M. Marcus, J.B. Nicholas, Acc. Chem. Res. 36 (2003) 317.

[17] Y. Liu, S. Müller, D. Berger, J. Jelic, K. Reuter, M. Tonigold, M. Sanchez-Sanchez, J.A. Lercher, Angew. Chem., Int. Ed 55 (2016) 5723.

[18] U. Olsbye, S. Svelle, M. Bjørgen, P. Beato, T.V.W. Janssens, F. Joensen, S. Bordiga, K.P. Lillerud, Angew. Chem., Int. Ed. 51 (2012) 5810.

[19] S. Ilias, A. Bhan, ACS Catal. 3 (2013) 18.

[20] M. Bjørgen, S. Svelle, F. Joensen, J. Nerlov, S. Kolboe, F. Bonino, L. Palumbo, S. Bordiga, U. Olsbye, J. Catal. 249 (2007) 195.

[21] S. Müller, Y. Liu, M. Vishnuvarthan, X. Sun, A.C. van Veen, G.L. Haller, M. Sanchez-Sanchez, J.A. Lercher, J. Catal. 325 (2015) 48.

[22] X. Sun, S. Mueller, H. Shi, G.L. Haller, M. Sanchez-Sanchez, A.C. van Veen, J.A. Lercher, J. Catal. 314 (2014) 21.

[23] S. Svelle, F. Joensen, J. Nerlov, U. Olsbye, K.P. Lillerud, S. Kolboe, M. Bjørgen, J. Am. Chem. Soc. 128 (2006) 14770.

[24] M. Choi, K. Na, J. Kim, Y. Sakamoto, O. Terasaki, R. Ryoo, Nature 461 (2009) 246.

[25] H. Awala, J.P. Gilson, R. Retoux, P. Boullay, J.M. Goupil, V. Valtchev, S. Mintova, Nat Mater 14 (2015) 447.

[26] S. Mintova, J.P. Gilson, V. Valtchev, Nanoscale 5 (2013) 6693.

[27] T. Armaroli, L.J. Simon, M. Digne, T. Montanari, M. Bevilacqua, V. Valtchev, J. Patarin, G. Busca, Appl. Catal. A 306 (2006) 78. 
[28] B. Louis, S. Walspurger, J. Sommer, Catal. Lett. 93 (2004) 81.

[29] C. Pereira, R.J Gorte, Appl. Catal. A 90 (1992) 145.

[30] Dispersity: http://www.iupac.org/publications/pac/81/2/0351/

[31] P. R. Willmott, Synchrotron Radiat. 20 (2013) 667.

[32] A.A. Coelho, Indexing of powder diffraction patterns by iterative use of singular value decomposition, J. Appl. Crystallogr. 36 (2003) 86-95.

[33] A.A. Coelho, TOPAS-ACADEMIC v5.0. 2012.

[34] CrystalMaker Software Ltd., O., UK, http://www.crystalmaker.com.

[35] J. Graesslin, PhD. Thesis, ETH Zurich, 2013.

[36] W. Cha, N.C. Jeong, S. Song, H. Park, T. Cao, T. Pham, R. Harder, B. Lim, G. Xiong, D. Ahn, I. McNulty, J. Kim, K.B. Yoon, I.K. Robinson, H. Kim, Nat. Mater. 12 (2013) 729.

[37] a) Chemical Reactor Analysis \& Design ( $2^{\text {nd }}$ Ed.), G.F. Froment, K.B. Bischoff, 1990, John Wiley \& Sons b) Fundamentals of Chemical Reaction Engineering ( $1^{\text {st }}$ Ed.), M.E. Davis, R.J. Davis, 2003, The McGraw-Hill Companies Inc.

[38] E.M. Flanigen, B.M. Lok, R.L. Patton, S.T. Wilson, Y. Murakami, A. Ijima, (Eds.), New Developments in Zeolite Science and Technology, J.W. Ward, Kodansha Press, Tokyo, 1986, p. 103.

[39] Y. Xu, P.J. Maddox, J.M. Couves, J. Chem. Soc., Faraday Trans. 86 (1990) 425.

[40] F.L. Bleken, S. Chavan, U. Olsbye, M. Boltz, F. Ocampo, B. Louis, Appl. Catal. A 447-448 (2012) 178.

[41] P. Losch, G. Laugel, J.S. Martinez-Espin, S. Chavan, U. Olsbye, B. Louis, Top. Catal. 58 (2015) 826.

[42] P. Losch, M. Boltz, B. Louis, S. Chavan, U. Olsbye, Comptes Rendus Chim. 18 (2015) 330.

[43] C. Baerlocher, L.B. McCusker, D.H. Olson, Atlas of Zeolite Framework Types; Elsevier: Amsterdam, 2007 and C. Baerlocher, L.B. McCusker, Database of Zeolite Structures http://www.iza-structure.org/databases/.

[44] C. Baerlocher, A. Hepp, W.M. Meier, DLS-76, a FORTRAN program for the simulation of crystal structures by geometric refinement, Institut für Kristallographie und Petrographie, ETH Zürich, Switzerland 1978.

[45] C.A. Fyfe, D.H. Brouwer, A.R. Lewis, J.M. Chezeau, J. Am. Chem. Soc. 123 (2001) 6882.

[46] H. van Koningsveld, J.C. Jansen, H. van Bekkum, Zeolites 7 (1987) 564.

[47] S. Nair, M. Tsapatsis, J. Phys. Chem. 104 (2000) 8982.

[48] C.A. Fyfe, J.S.J. Lee, L.M.D. Cranswick, I. Swainson, Microporous Mesoporous Mater. 112 (2008) 299.

[49] J.L. Guth, L. Delmotte, M. Soulard, N. Brunard, J.F. Joly, D. Espinat, Zeolites 12 (1992) 929.

[50] P. Barger, Methanol-to-olefins and beyond, in Zeolites for Cleaner Technology, Eds. M. Guisnet, J.P. Gilson, Vol 3, 2002, Imperial College Press, London, England.

[51] E. Buncel, C.C. Lee, Isotopes in Organic Chemistry. Vol. 5, 1977, Elsevier: Amsterdam.

[52] K. Mislow, R. Graeve, A.J. Gordon, G.H. Wahl, J. Am. Chem. Soc. 85 (1963) 1199.

[53] a) T. Felder, C.A. Schalley, Angew. Chem. Int. Ed.42 (2003) 2258; b) F.H. Westheimer, Chem. Rev. 61 (1961), 265.

[54] a) J.A. Lercher, A. Jentys, Application of Microporous Solids as Catalysts, in Handbook of Porous Solids, Eds. F. Schuth, K.S.W. Sing, J. Weitkamp, Vol 2, 2002, Wiley-VCH Verlag GmbH, Weinheim, Germany; b) C. Bernardon, B. Louis, V. Beneteau, P. Pale, ChemPlusChem 78 (2013) 1134.

[55] M. Hunger, J. Kärger, H. Pfeifer, J. Caro, B. Zibrowius, M. Bülow, R. Mostowicz, J. Chem. Soc. Faraday Trans. 83 (1987) 3459.

[56] P. Kortunov, S. Vasenkov, J. Kärger, R. Valiullin, P. Gottschalk, M.F. Eläa, M. Perez, M. Stöcker, B. Drescher, G. McElhiney, C. Berger, R. Gläser, J. Weitkamp, J. Am. Chem. Soc. 127 (2005) 13055.

[ 57 ] D. Schneider, D. Mehlhorn, P. Zeigermann, J. Kärger, R. Valiullin, Chem. Soc. Rev. (2016) 10.1039/C5CS00715A.

[58] R.R. Mukti, Sorption and transport of aromatic over MFI zeolites 2007.

[59] This order of magnitude $600 \cdot 10^{-9} \mathrm{~m}^{2} \cdot \mathrm{s}^{-1}$ is common for gas phase diffusion in ZSM-5 zeolites. For $\mathrm{CH}_{4}$ : $D_{\text {eff }}=900-1900.10^{-9} \mathrm{~m}^{2} \cdot \mathrm{s}^{-1}$ S.S. Arzumanov, D.I. Kolokolov, D. Freude, A.G. Stepanov, J. Phys. Chem. C 119 (2015) 18481.

[60] E.G. Derouane, J.M. André, A.A. Lucas, Chem. Phys. Lett. 137 (1987) 336.

[61] C. Rajappa, C. Krause, B.J. Borah, Z. Adem, P. Galvosas, J. Kärger, Y. Subramanian, Microporous Mesoporous Mater. 171 (2013) 58.

[62] D. Mores, J. Kornatowski, U. Olsbye, B.M. Weckhuysen, Chem. Eur. J. 17 (2011) 2874. 
[63] Q. Qian, J. Ruiz-Martínez, M. Mokhtar, A.M. Asiri, S.A. Al-Thabaiti, S.N. Basahel, B.M. Weckhuysen, ChemCatChem 3 (2014) 668-678.

[64] J.P. Hofmann, D. Mores, L.R. Aramburo, S. Teketel, M. Rohnke, J. Janek, U. Olsbye, B.M. Weckhuysen, Chem. Eur. J. 19 (2013) 8533-8542.

[65] J.E. Schmidt, J.D. Poplawsky, B. Mazumder, Ö. Attila, D. Fu, D.A.M. De Winter, F. Meirer, S.R. Bare, B.M. Weckhuysen, Angew. Chem. Int. Ed 55 (2016) 11173.

[66] C. Kemball, Adv. Catal. 2 (1950) 233.

[67] B. Smit, T.L.M. Maesen, Nature 451 (2008) 671.

[68] E.G. Derouane, Chem. Phys. Lett. 142 (1987) 200.

[69] Kim, J.; Choi, M.; Ryoo, R. J. Catal. 2010, 269, 219.

[70] Y. Zhi, H. Shi, L. Mu, Y. Liu, D. Mei, D.M. Camaioni, J.A. Lercher, J. Am. Chem. Soc. 137 (2015) 15781.

[71] W.O. Haag, R.M. Lago, P.B. Weisz, Nature 309 (1984) 589.

[72] I. Krossing, I. Raabe, Angew. Chem., Int. Ed. 43 (2004) 2066.

[73] T.Y. Park, G.F. Froment, Ind. Eng. Chem. Res. 40 (2001) 4187.

[74] R. Gounder, E. Iglesia, Acc. Chem. Res. 45 (2012) 229.

[75] A.J. Jones, R.T. Carr, S.I. Zones, E. Iglesia, J. Catal. 312 (2014) 58.

[76] E.G. Derouane, Microporous Mesoporous Mater. 104 (2007) 46.

[77] U. Pisani, Acustica, 25 (1976) 133.

[78] Y. Inokuma, S. Yoshioka, J. Ariyoshi, T. Arai, Y. Hitora, K. Takada, S. Matsunaga, K. Rissanen, M. Fujita, Nature 495 (2013) 461.

[79] A. Szarpak-Jankowska, C. Burgess, L. De Cola, J. Huskens, Chem. Eur. J. 19 (2013) 14925. 


\section{Figure Captions}

Scheme 1. MTO on H-ZSM-5: Generally accepted reaction pathways at quasi steady-state conditions producing high amounts of propylene.

Table 1. Textural properties of H-ZSM-5F zeolites.

Table 2. Catalysts activities and selectivities in the methanol-to-hydrocarbons reaction.

Figure 1. SEM images of as-synthesized zeolites: a) ZSM-5FN b) ZSM-5FLD c) ZSM-5FS and d) ZSM-5FL. Inserts show crystal size distributions (counts on the y axis and crystal sizes in nm on the $\mathrm{x}$ axis) as well as calculated dispersities (Đ).

Figure 2. HRTEM and EDX analysis showing a perfectly homogeneous distribution of Al in assynthesized ZSM-5FL crystal (cf. entry 3 in Table 1).

Figure 3. View of the MFI structure of sample ZSM5-FL down the b-axis, showing the $4 \mathrm{TPA}^{+}$cations per unit cell. The green balls represent the location of fluoride anions. Framework oxygen atoms have been omitted for clarity.

Figure 4. ${ }^{19} \mathrm{~F}$ MAS NMR for $\mathrm{NH}_{4}$-forms of ZSM-5FL and ZSM-5FLD zeolites; insert: ${ }^{27} \mathrm{Al}$ MAS NMR for the same samples.

Figure 5. Low temperature CO adsorption FT-IR for a) H-ZSM-5FLD and b) H-ZSM-5FL. FT-IR spectra after pre-treatment at $873 \mathrm{~K}$ for $1 \mathrm{~h}$, following $\mathrm{CO}$ adsorption at $77 \mathrm{~K}$. Insert: the $\mathrm{v}(\mathrm{OH})$ region; while the main graph presents the $v(\mathrm{CO})$ region. The $\mathrm{CO}$ coverage decreases successively from bold grey curve to light grey curve in the spectrum.

Figure 6. ZSM-5FLD catalyst selectivities at different reaction temperatures acquired at full conversion of a) $\mathrm{d}_{4}-\mathrm{MeOD}$ and b) $\mathrm{MeOH}$. Product distribution: $\mathbf{C}_{1-4}$ black, $\mathbf{C}_{2}=$ clear blue, $\mathbf{C}_{3}=$ dashed, $\mathbf{C}_{4}=$ white,

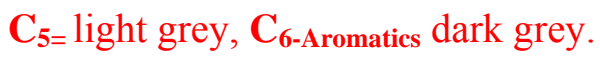

Figure 7. Distribution of products formed (Product distribution: $\mathbf{C}_{1-4}$ black, $\mathbf{C}_{2}=$ clear blue, $\mathbf{C}_{3}=$ dashed,

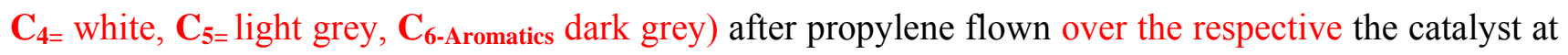
different temperatures $\left(250-550^{\circ} \mathrm{C}\right)$ : a) H-ZSM-5FN b) H-ZSM-5FLD c) H-ZSM-5FL. In d) is represented the methanol conversion as a function of the time on stream (TOS) for H-ZSM-5FL, HZSM-5FN and H-ZSM-5FLD. (WHSV $(\mathrm{MeOH})=1.2 \mathrm{~h}^{-1} ; \mathrm{T}=450^{\circ} \mathrm{C} ; 60 \mathrm{mg}$ catalyst)

Figure 8. PFG NMR diffusion experiments over H-ZSM-5FN (yellow), H-ZSM-5FLD (red) and HZSM-5FL (blue) with three different probe molecules a) toluene, b) benzene and c) neopentane. 
Figure 9. Probability of encountering a next active site (located in the blue spherical channel intersections) traced as a function of channel intersections to diffuse through. A 4-unit cell model for inter active site distance modelling: acid sites, preferably located at channel intersections (blue spheres) are more dispersed with increasing Si/Al-ratio: a molecule diffusing through the microporous network of H-ZSM-5FL, for instance, would diffuse through at least 5-6 other channel intersections before encountering a next acid site. 


\section{Scheme 1.}

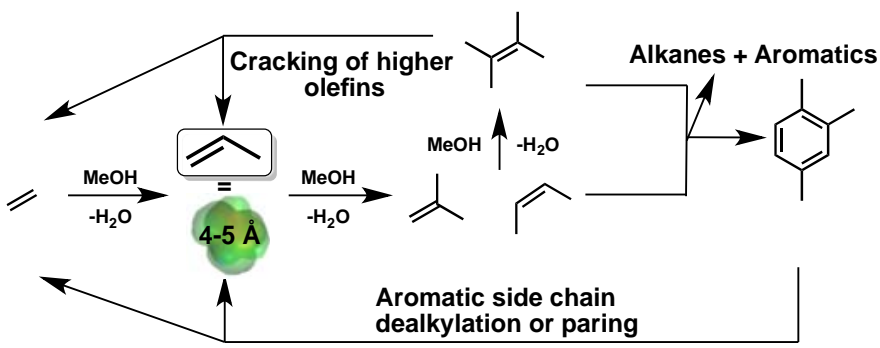

Table 1.

\begin{tabular}{llllllll}
\hline Entry & Zeolite & $\begin{array}{l}\text { Si/Al- } \\
\text { ratio }\end{array}$ & $\begin{array}{l}\text { Theoretical acid site } \\
\text { density } \\
{\left[\operatorname{mmol}\left(\mathrm{H}^{+}\right) \cdot \mathrm{g}_{\text {zeolite }}{ }^{-1}\right]}\end{array}$ & $\begin{array}{l}\text { Acid } \\
{\left[\mathrm{mmol}\left(\mathrm{H}^{+}\right) \cdot \mathrm{g}_{\text {zeolite }}^{-1}\right]} \\
\mathrm{a}\end{array}$ & $\begin{array}{l}\text { site } \\
{\left[\mathrm{m}^{2} \cdot \mathrm{g}^{-1}\right]}\end{array}$ & $\begin{array}{l}\mathrm{S}_{\text {meso }} \\
{\left[\mathrm{m}^{2} \cdot \mathrm{g}^{-1}\right]}\end{array}$ \\
\hline 1 & H-ZSM-5FN & 137 & 0.13 & 0.36 & 0.144 & 288 & 92 \\
2 & H-ZSM-5FS & 139 & 0.13 & 0.21 & 0.127 & 425 & 55 \\
3 & H-ZSM-5FL & 139 & 0.13 & 0.18 & 0.135 & 412 & 52 \\
4 & H-ZSM-5FLD & 104 & 0.13 & 0.45 & 0.181 & 348 & 126 \\
\hline
\end{tabular}

a: Total amount of exchangeable hydrons: titrated by isotope H/D-exchange technique.

b: Si-(OH)-Al bridging sites related Brønsted acid sites (BAS) quantified by propylamine-TPD.

Table 2.

\begin{tabular}{lllllllll}
\hline Entry & Zeolite & Conversion [\%] & \multicolumn{7}{l}{ Selectivities [\%] } \\
\hline & & & $\mathrm{CH}_{4}-\mathrm{C}_{4} \mathrm{H}_{10}$ & $\mathrm{C}_{2}=$ & $\mathrm{C}_{3}=$ & $\mathrm{C}_{4}=$ & $\mathrm{C}_{5=}$ & $\mathrm{C}_{6+}$ aromatics \\
\hline 1 & H-ZSM-5FN & 99 & 4 & 16 & 39 & 15 & 16 & 10 \\
2 & H-ZSM-5FS & 99 & 4 & 6 & 42 & 19 & 21 & 8 \\
3 & H-ZSM-5FL & 99 & 1 & 6 & 45 & 19 & 20 & 9 \\
4 & H-ZSM-5FLD & 99 & 7 & 20 & 35 & 13 & 14 & 11 \\
$5^{\text {a }}$ & H-ZSM-5FLD & 99 & 1 & 10 & 44 & 18 & 19 & 8
\end{tabular}

Catalytic data obtained after $1 \mathrm{~h}$ on stream under standard conditions; $60 \mathrm{mg}$ catalyst in a fixed-bed quartz reactor, $450^{\circ} \mathrm{C}$, WHSV $1.2 \mathrm{~h}^{-1}$; ${ }^{a}$ Experiment carried out with $\mathrm{d}_{4}$-methanol to evidence an isotope effect 


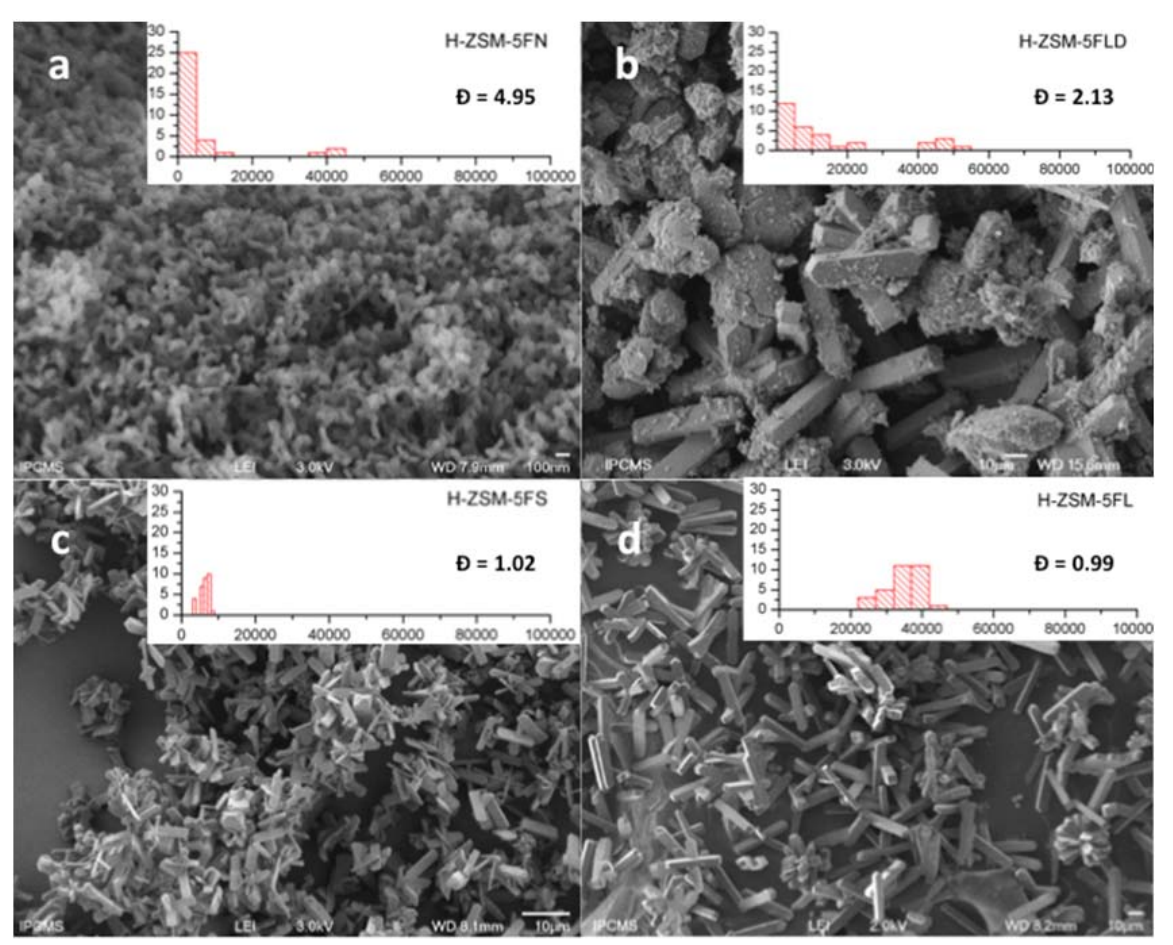

Figure 1.
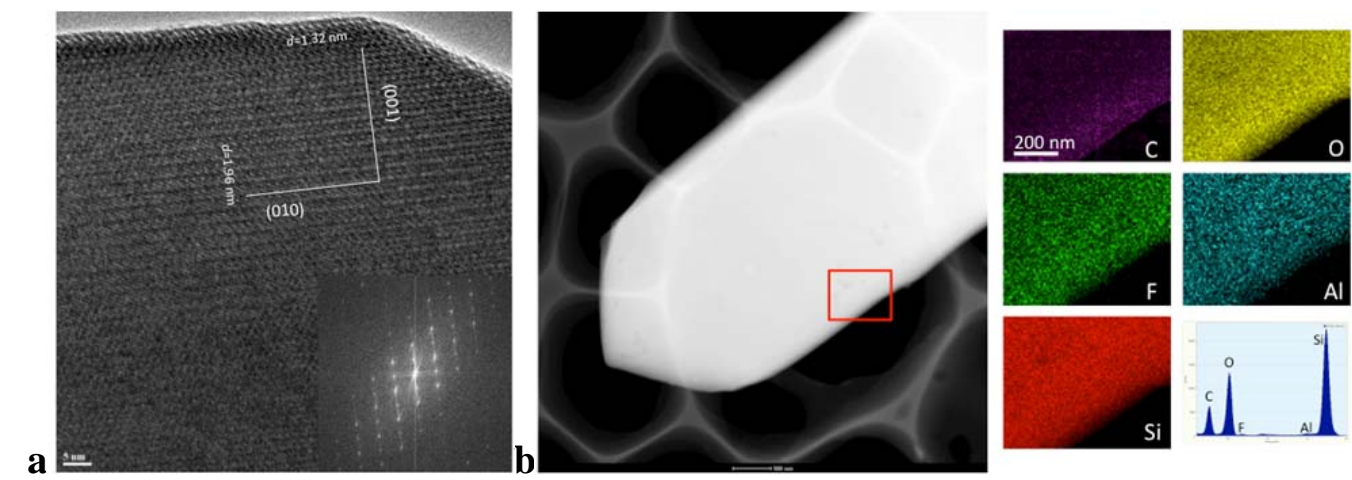

Figure 2.

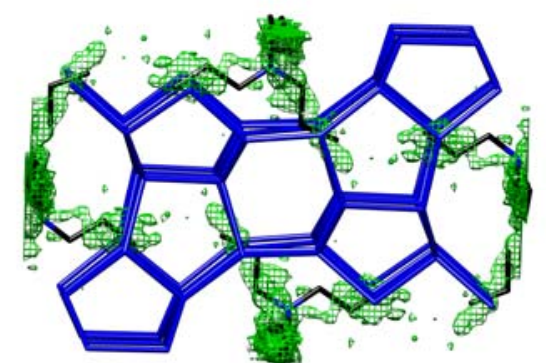

a

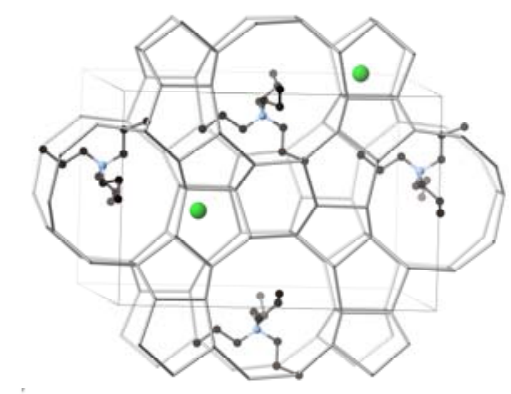

Figure 3. 


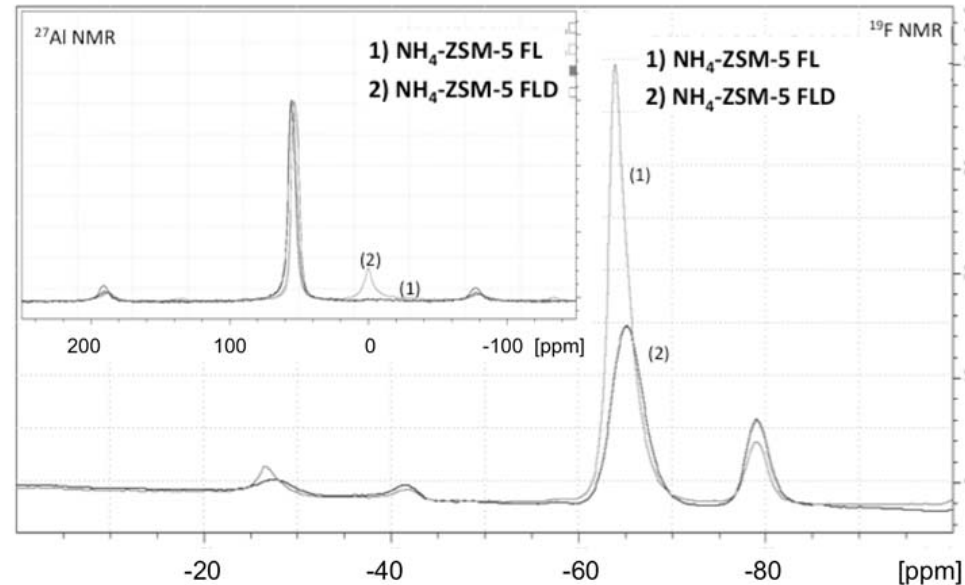

Figure 4.
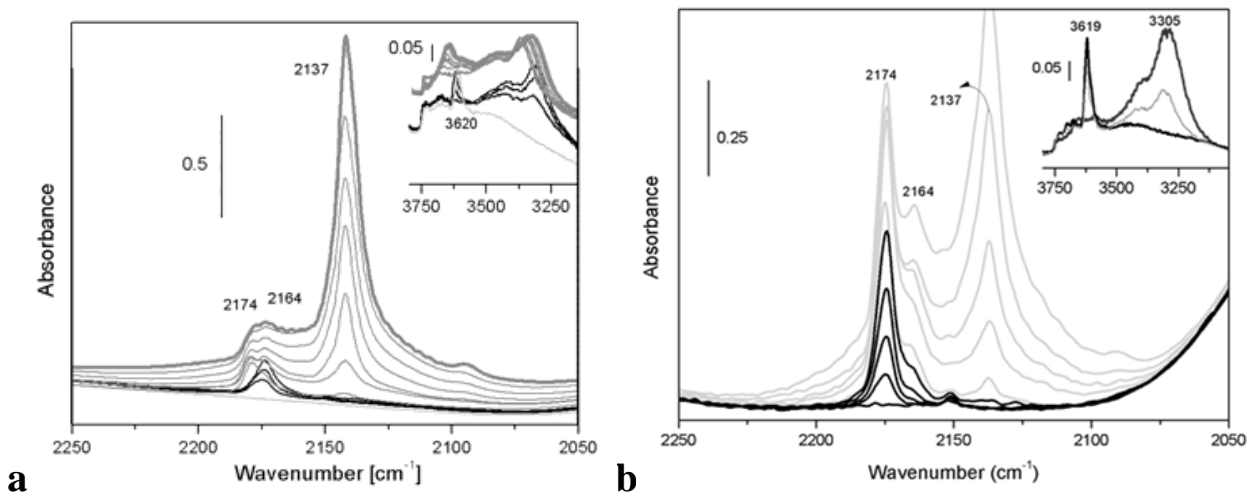

Figure 5.
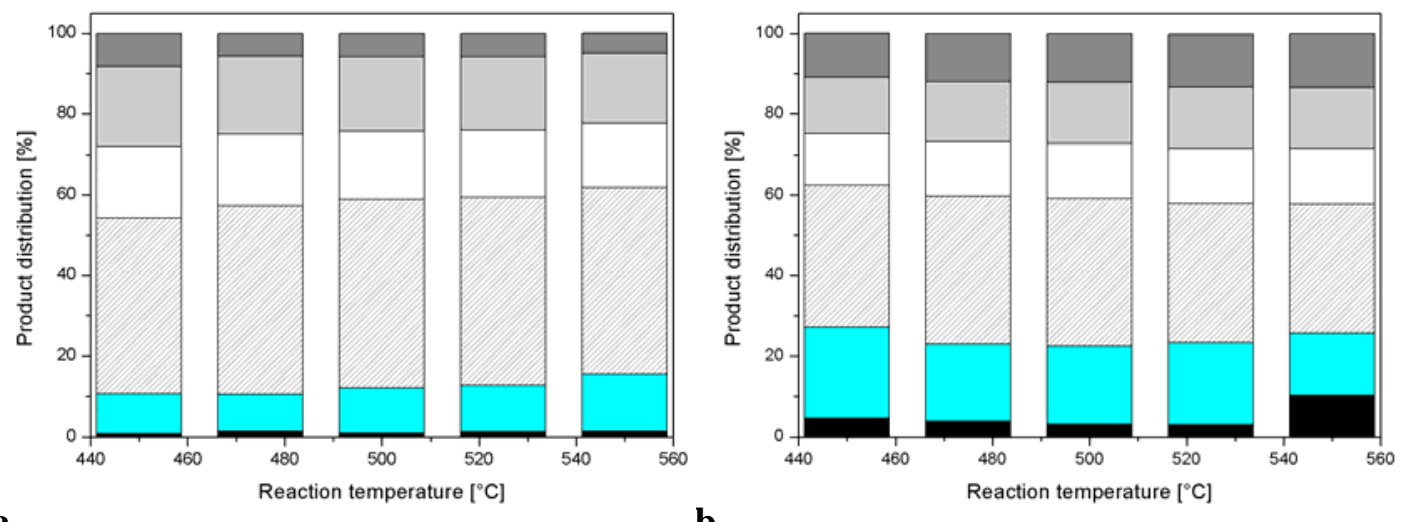
b

Figure 6. 

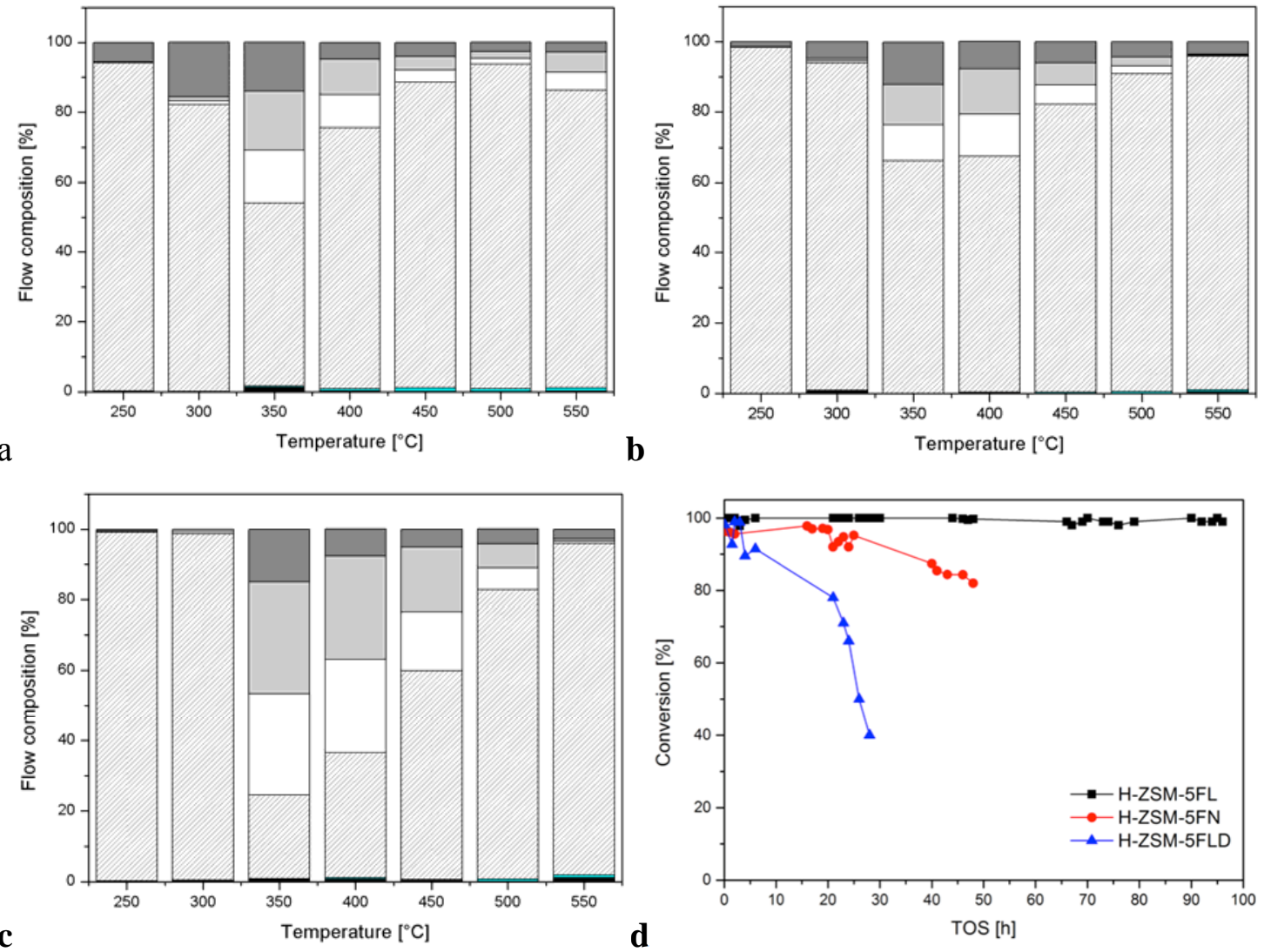

Figure 7.
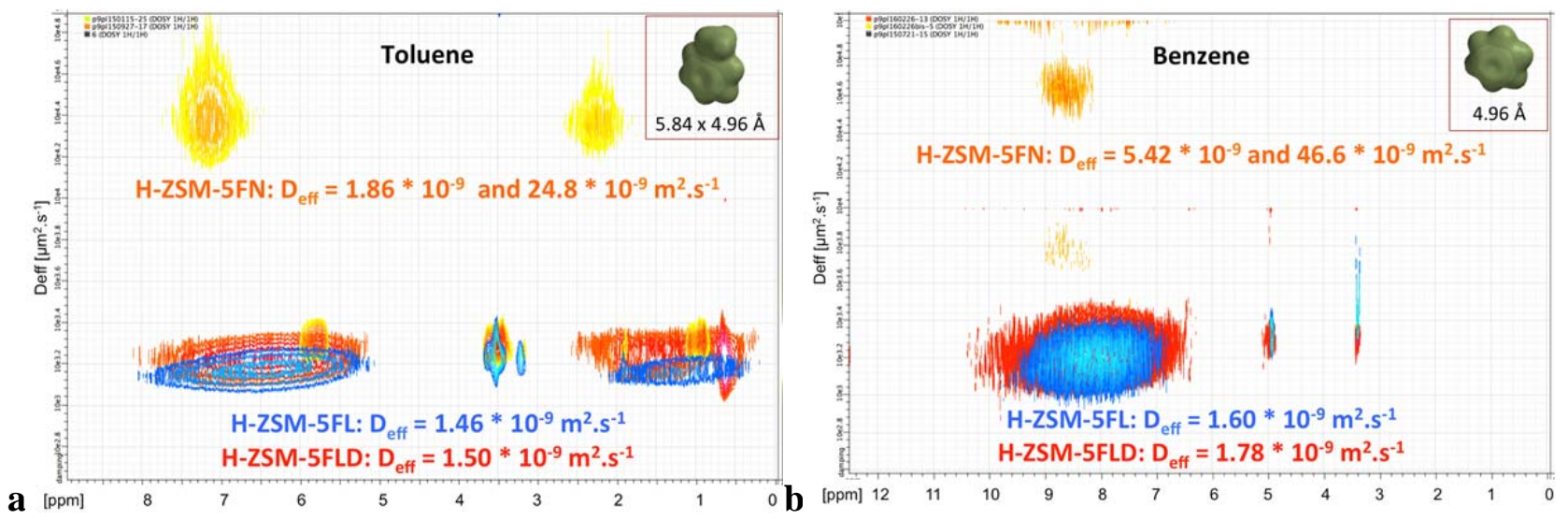


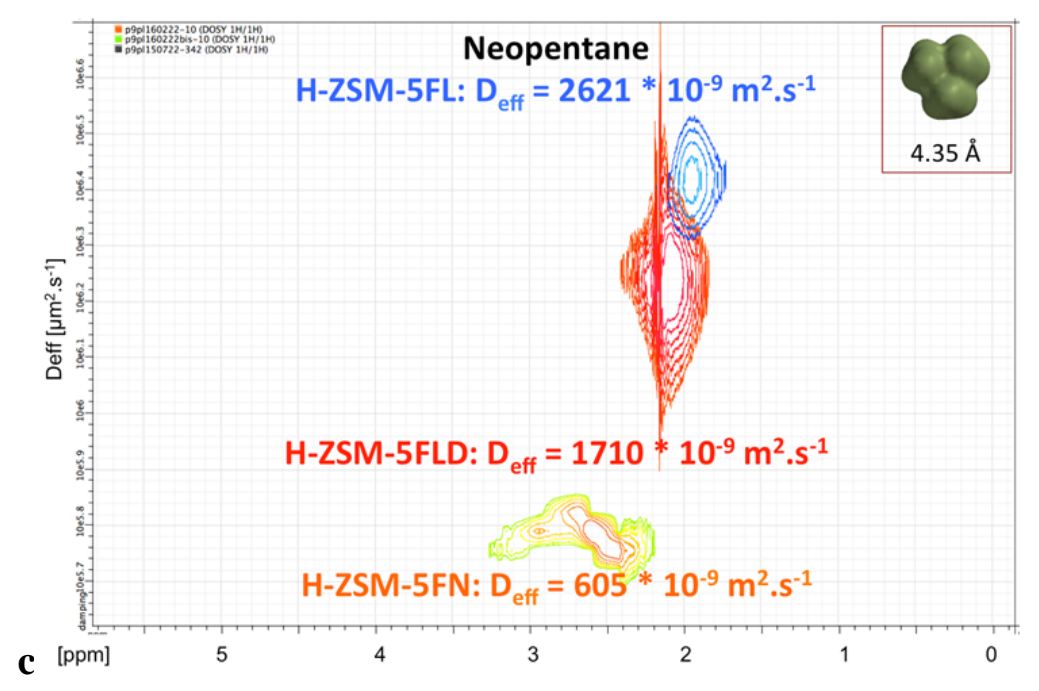

Figure 8.
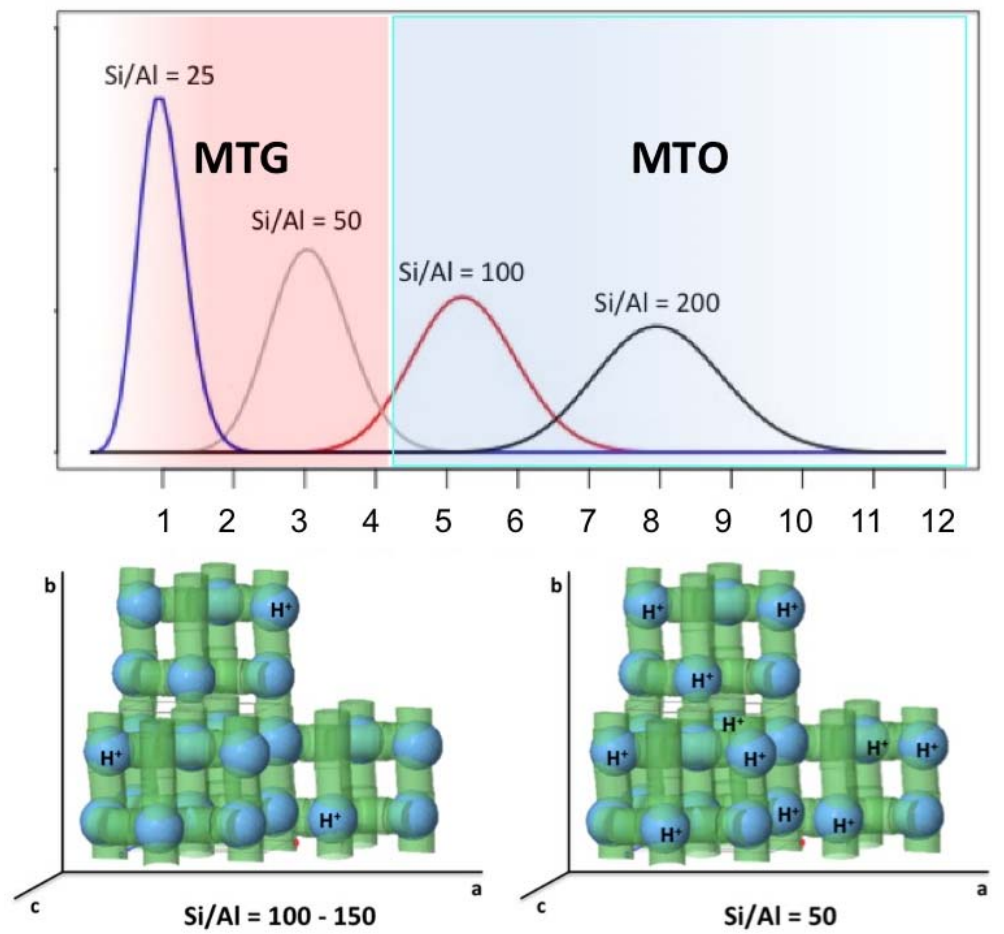

Figure 9. 


\section{Graphical Abstract}

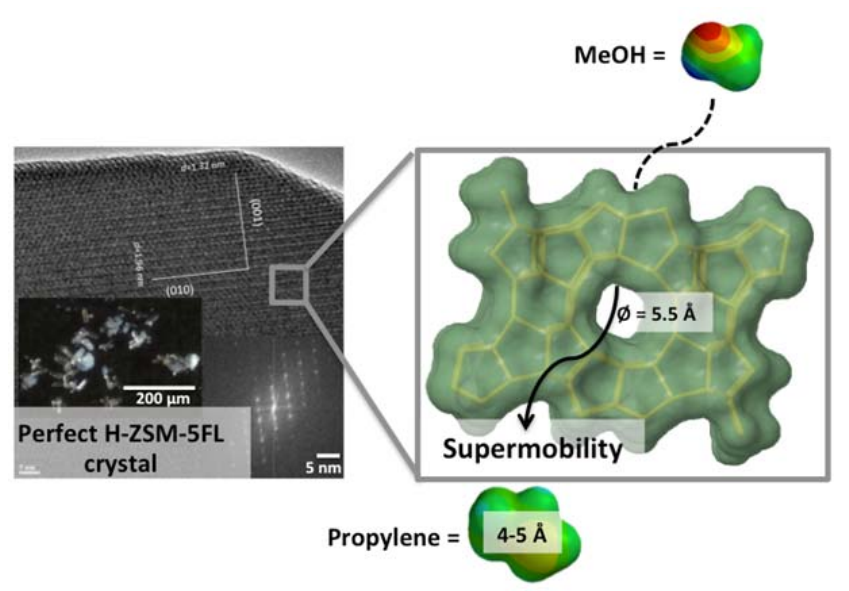

